\title{
A New Test of Capital Structure
}

\author{
Colin Mayer and Oren Sussman
}

\author{
Wadham College \\ Saïd Business School \\ University of Oxford
}

October 6, 2004

This paper has been presented at seminars in Bologna, Buenos Aires, Copenhagen, Oslo, St. Andrews, the Stockholm School of Economics, the European Summer Symposium in Financial Markets at Gerzensee (2002) and the "Understanding Financial Architecture" conference in Oxford (2002). We are grateful to Franklin Allen, Patrick Bolton, Denis Gromb, Zhangkai Huang, Vojislav Maksimovic, Stewart Millman, Kjel Nyborg, Marco Pagano, Kristian Rydqvist, Alex Stomper and Paolo Volpin for helpful suggestions. We are grateful to Zhangkai Huang for excellent research assistance and we thank the Peter Moores Foundation for financial support.

Corresponding author: Colin Mayer, Saïd Business School, University of Oxford, Park End Street, Oxford OX1 1HP, UK, telephone: +44 1865 288919, fax: +44 1865 288805, email: colin.mayer@sbs.ox.ac.uk 


\title{
A New Test of Capital Structure
}

\begin{abstract}
We report results of a new test of the financing of large and indivisible projects arguably the focus of most capital structure theory. We develop a filter that identifies investment spikes in a large population of firms. Consistent with the pecking-order theory we find that projects are predominantly financed with debt, particularly in large and profitable firms. However, we reject the hypothesis that internal finance plays a major role in funding investment. Consistent with the trade-off theory, firms show a strong tendency to revert back to their initial leverage. This pattern of "pecking order in the short run, trade-off in the long run" is consistent with equity adjustment being postponed until certain thresholds are reached. However, we do not find evidence that equity issues are lumpy or infrequent.
\end{abstract}

Key words: Capital structure, pecking order theory, trade-off theory.

JEL classification: G32 . 


\section{A New Test of Capital Structure}

"We have seen that on average internal funds (depreciation plus retained earnings) make up the bulk of money that companies need [for investment]. ... Why, then do managers have an apparent preference for financing by retained earnings?" Brealey and Myers (2000), p. 385.

"Internal finance is a more important source of funds than debt or equity for investment" Allen and Gale (2000), pp. 15 - 16.

\section{Introduction}

That internal finance is the main source for funding new investment is common wisdom in corporate finance. It is based on numerous empirical studies, ${ }^{1}$ and has motivated some of the most influential theories of capital structure, most notably the pecking-order theory. In this paper we present no new data; indeed, the only information that we use is taken from the much-exploited Compustat database. However, we demonstrate that the same data can be aggregated, analysed and interpreted in a different manner and, once that is done, new theoretical insights emerge.

To gain a better understanding of our concerns about existing evidence, consider the numerical examples in Table 1. Three hypothetical firms need to fund an equal amount of investment over a three-year period. The cash receipts of the three firms are identical. However, firm A's investment is spread over time, so that its cash flow from operations is sufficient to fund it on an annual basis, unlike firms B and C whose investments are lumpy and too large to be funded from annual cash flows. Firm $\mathrm{B}$ is also financed internally but in this case by accumulating cash flows in a liquid fund prior to the execution of the project and then utilizing this fund. Only firm $\mathrm{C}$ is externally financed, borrowing in order to fund the investment and paying it back after the project is executed. The crucial point is that once the flow-of-funds are aggregated over time, all three firms look identical, irrespective of whether they use internal or external finance.

\footnotetext{
${ }^{1}$ See, for example, Corbett and Jenkinson (1997), Mayer (1988) and Rajan and Zingales (1995).
} 
Flow-of-funds data aggregated over time cannot therefore determine whether investment is internally or externally financed. All they record is whether firms are on balance net recipients of external sources and if they earn a positive return (net of depreciation) then the answer to that is clear: they will in general have adequate funds to finance their investments internally. The question that needs to be answered, and cannot be by aggregate data, is whether external or accumulated internal sources are used during periods of potential cash shortage, when investment expenditures exceed cash flows from operations. To answer that, one needs to identify incidents of potential cash shortages and to isolate these from flows at other times. One also needs to avoid pooling potentially cash-short firms with those that face no cash shortage (i.e. firms like $\mathrm{B}$ and $\mathrm{C}$ with firms like $\mathrm{A}$ in the hypothetical example above). In other words, one requires a mechanism for recording flows of finance during investment spikes.

That is the approach taken in this paper. It filters out a sample of large investment events, identified as yearly spikes in firm-level investment data, double (or more) the size of a "base level of investment" observed immediately prior to and after the spike. This yields a dataset with 535 investment events, each of fixed five-year duration with an investment spike in the middle. Having identified firms (and occasions) of potential cash shortage, we can then test several hypotheses regarding capital-structure theory, including the specific question with which we started: is (large) investment internally or externally financed? We shall consider below the possible problems of selection bias that can arise when inferences are drawn from a truncated sample. Suffice it to say here that by focusing on large investment events we do not throw away information; on the contrary, we prevent firms in "repayment regimes" from clouding those in "investment regimes" thereby decreasing the power of the tests.

Beside their attractive statistical properties, there are two additional reasons why investment spikes are interesting. First, such spikes are the focus of nearly all modern corporate finance theory. Typically, a theoretical model starts by specifying a setting in which a penniless entrepreneur is endowed with an indivisible investment 
opportunity, termed a "project". Lumpy investment is therefore important for testing theory, irrespective of the frequency with which it appears in the data.

Second, investment spikes are of considerable practical importance. Doms and Dunne (1997) order a population of 358,567 manufacturing plants surveyed in the 1987-Census according to the (net) growth rate of their capital stock. They report that the top 500 investment spikes account for $32 \%$ of the survey's total investment, while the bottom 308,567 investment events account for only $6.5 \%$ of total investment. ${ }^{2}$ Trying to simulate the empirical size-distribution with a structural model they find that a setting with "non-convex adjustment costs" (where capital adjustments are lumped together and then executed, as in Ss inventory theory) fits the data best. ${ }^{3}$ They also provide evidence that investment spikes tend to occur at critical points in firms' life cycles, in small and young firms, and plants that have undergone a recent restructuring (change of ownership or industry). ${ }^{4}$

We report four main results. First, in the short run during an investment spike, investment is predominantly funded with external finance, particularly in small firms. Aggregating flow of funds during a spike across firms we find that on average $114 \%$ (61\%) of spikes is externally funded in small (big) firms. Moreover, firms tend to raise external finance even before they have exhausted all internal resources. In a regression analysis, we find that at the margin, an additional dollar of current earnings decreases external funding by only 20 cents. As one might expect, a significant proportion of spikes are associated with acquisitions but we do not find that acquisitions are funded differently from internal investment.

The second set of results relates to the composition of short-run external financing. According to the pecking-order theory "debt comes first, equity is a last resort" so that "good" firms specialise in debt and other firms in equity finance. To a considerable extent, these predictions are borne out by the data, which reveal a predominance of debt over equity finance among large companies with many avoiding equity altogether. Companies that do issue equity seem to be under performers, while those that buy back equity are strong performers. In small firms, equity dominates debt (in the short run) and many are entirely dependent on equity finance. Hence, apart

\footnotetext{
${ }^{2}$ See Table II.

${ }^{3}$ See Fig 3 and its discussion.

${ }^{4}$ See Table III.
} 
from the limited role for internal finance, our results are quite consistent with the pecking-order theory in the short run.

A third result concerns the dynamics of capital structure in the longer run. According to the pecking order theory, leverage drifts randomly without a target in response to excesses and deficiencies of cash flows. We reject this hypothesis: over the five-year period around investment spikes, companies of all size groups show a strong tendency to revert back to their initial leverage. This tendency is clearest amongst large firms, which offset up to $70 \%$ of their accumulated disturbances to capital structure. We further show that reversion is achieved, not through a process of averaging positive and negative shocks over time, which would be consistent with the pecking-order theory, but by issuing equity. In addition, we reject the hypothesis that firms only adjust leverage when they are close to insolvency. Excluding high-leverage firms, we show that even firms that are well away from insolvency demonstrate reversion in capital structure. Interestingly, large firms that come closest to satisfying the pecking-order theory in the short run, display the greatest reversion in the long run.

Putting together the second and the third results, it might be thought that there are discrete adjustments to capital structure through lumpy equity issues (as in a Ss inventory model) along the lines suggested by Fisher, Heinkel and Zechner (1989). ${ }^{5}$ However, our fourth result does not support this theory: we find an abundance of small equity issues. For example, $22 \%$ of large firms and $35 \%$ of small firms issue equity four or five times in the five-year periods around investment spikes.

Our findings can be best summarized as suggesting that the pecking-order theory holds in the short run, while a target-leverage "trade-off theory" holds in the long run. That, however, is subject to the important qualifications about the limited role for internal finance and the absence of a satisfactory explanation of long-run dynamics. No single theory provides a comprehensive explanation for all aspects of the data.

The rest of the paper is organised as follows. After a short discussion of the related literature, Section 2 describes the theoretical background in more detail and formulates the testable hypotheses. Section 3 describes the data and the filtering technique. Section 4 presents an analysis of short-term funding of large investment

\footnotetext{
${ }^{5}$ See Strebulaev (2003) for a refinement of this argument, emphasising aggregation problems.
} 
events and Section 5 analyses long-term adjustments. Section 6 provides an analysis of the size and frequency of equity issues, and Section 7 concludes the article.

\section{Related Literature}

Among the older papers on capital structure, Bradley et al (1984) is particularly significant. They formulate the classic trade off theory between taxation and costs of financial distress and derive proxies for measuring these. They test the theory on twenty-year firm-level averages for 851 companies and find evidence to support it. Titman and Wessels (1988) use a factor-analytic approach to address the measurement problems created by the use of proxies. They test the model on a sample of 469 firms, using higher frequency data than Bradley et al. They fail to find support for the relevance of traditional factors such as tax-shields or volatility but they do find some support for other theories, for example, that firms with a unique line of business tend to have less debt. Although these studies do not employ filters, their sample sizes are of the same order of magnitude as the one used in this paper.

Until recently, there have been few attempts to test the pecking order theory directly. Shyam-Sunder and Myers (1999) are among the first to do so. They estimate a specification where changes in debt are a linear function of the "funds flow deficit" (capital expenditure minus internal cash flow and a few other items), and conclude that the evidence is consistent with the theory's prediction. In particular, the flow of funds deficit is found to be almost entirely debt financed. The study is restricted to firms that have complete records for the entire period 1971-1989, of which there are 157, with a clear bias towards old, large, surviving companies.

The results by Shyam-Sunder and Myers (1999) were attacked from two different directions. First, Frank and Goyal (2003) have shown that their results were affected by the bias of the samples towards established companies and that small firms are much more dependent on equity finance than suggested by Shyam-Sunder and Myers (1999). Even more seriously, when they nest both the pecking order and tradeoff theory in a joint specification, the pecking order theory fails to dominate. Their conclusions are rather negative: "many aspects of the evidence pose serious problems for the pecking order. But this does not mean that the information contained in the finance deficit is completely irrelevant". 6

\footnotetext{
${ }^{6}$ See p. 241.
} 
The second attack came from Chirinko and Singha (2000) who argue that the Shyam-Sunder and Myers' test is mis-specified since the pecking-order model is inherently non-linear. Under the null hypothesis, as funding requirements increase (or internal resources dwindle) firms move from a regime of internal finance to debt and then to equity; clearly, the role of debt and equity is different in the various regimes. As a result, a unit coefficient in a Shyam-Sunder and Myers regression is neither a necessary nor a sufficient condition for the pecking order theory to be valid; it can fall well short of unity when the pecking order theory holds and be close to unity when it does not.

Our methodology helps to resolve some of these problems. Firstly, the filter is specifically designed to capture the potential non-linear relation between financing requirements and forms of finance. We show explicitly how the forms of funding vary as firms move from one regime to another. Our results confirm and reinforce many of the findings in Frank and Goyal (2003) (for example, the strong reliance of small firms on equity) and highlight additional difficulties with the pecking-order theory, in particular, the weak reliance of even large firms on internal funds. Second, we identify the regime in which the information content of financial deficits is particularly relevant, namely during investment spikes. In terms of evaluating the pecking-order theory, we stand between Frank and Goyal (2003) and Shyam-Sunder and Myers (1999), recognising its predictive power in the short run, but also its limitations in the long run.

Another relevant paper is Fama and French (2002), which contrasts the pecking order and trade-off theories in cross-section regressions of Compustat firms over the period 1965 to 1999. Particularly noteworthy is the fact that our leverage-reversion rates - about $70 \%$ in five years - are consistent with theirs of between $7 \%$ and $18 \%$ annually. $^{7}$ However, we also provide several further refinements of their dynamic results, namely that reversion is associated with equity issues and occurs even among firms that are not close to insolvency.

Baker and Wurgler (2002) report that attempts by firms to time new equity to coincide with high valuations of their stock prices have persistent effects on their capital structures. They argue that capital structures are the cumulative product of these historical timing responses rather than the outcome of a dynamic optimisation

\footnotetext{
${ }^{7}$ See p. 24.
} 
process. In a similar vein, Welch (2004) records that changes in capital structure principally occur in response to equity market returns, again with little evidence of optimisation behaviour. However, Leary and Roberts (2004) suggest that the persistence in capital structure documented in these papers is due to adjustment costs rather than to indifference of firms to their capital structures. This paper is consistent with Leary and Roberts in finding that capital structures gradually revert to previous levels following a period of substantial funding requirements.

\section{Theory and Propositions}

There are two main contending theories of capital structure: the trade-off and the pecking-order theories. According to the trade-off theory, there are advantages and drawbacks to the use of debt - as against equity - and firms select an optimal capital structure that balances these at the margin. Initially, the theory was restricted to the trade-off between the tax advantages of debt and its effects on the probability of bankruptcy. Subsequently it was extended to include the trade-off between debt and equity arising from agency problems. For example, debt improves corporate governance by limiting "empire building" and "free cash flow" problems, but also encourages excessive risk taking and gambling for resurrection (see Harris and Raviv (1991)).

The paper by Myers and Majluf (1984) is often considered to be the theoretical underpinning of the pecking order theory. In this model, there are "good" and "bad" firms and asymmetries of information about firm type between managers and investors: managers know their own type better than investors. As a consequence, when firms issue new securities to fund projects, the markets (mis-)price the claims: the securities of the good (bad) firms are underpriced (overpriced) relative to their true underlying value. Crucially, however, the scale of the mispricing depends on the "information sensitivity" of the security issued: riskless debt is not mispriced at all, while equity is more severely mispriced than risky debt.

The underpricing of the good firms' securities results in a net transfer of value from existing shareholders to new investors. If managers maximise the value of existing shareholders' investments then they finance new projects with the least information-sensitive instrument. So if good firms invest at all, they finance it with debt rather than equity. Bad firms pool with good firms and issue debt as well; if they 
try to exploit the overpricing of their securities by issuing equity, the market separates them out and adjusts their prices accordingly. Since internal finance is free of any agency problem and thus mispricing, managers prefer this form of funding to any external finance, debt or equity.

It is important to recognise that the Myers-Majluf model does not provide a theory of capital structure. Rather, it is a theory of debt, which predicts that equity is dominated by debt and thus is never issued in equilibrium. Nevertheless, Myers (1984) argues that the model can be stretched to a theory of capital structure by ranking securities by their information sensitivity. In equilibrium, firms avoid mispricing by working down the pecking order ladder: "investment is financed first with internal funds, ... then by new issues of debt; and finally with new issues of equity. New equity issues are a last resort when the company runs out of debt capacity, that is, when the threat of costs of financial distress brings regular insomnia ... to the financial manager" (Brealey and Myers p. 524). Therefore "good" firms use debt while "bad" firms use equity: "it's better to be at the top of the pecking order than at the bottom. Firms that have worked down the pecking order and need external equity may end up ... passing by good investment" (Brealey and Myers p. 527). Though the pecking order theory recognises the logic of the trade-off theory, it denies its quantitative significance (at least at non-extreme levels of leverage): "the attraction of interest tax shield and the threat of financial distress are assumed second order" (Shyam-Sunder and Myers (1999)).

Some authors have tried to bridge the gap between the Myers-Majluf model and a pecking-order theory à la Brealey and Myers. For example, Stein (1992) suggests a framework in which firms face both an adverse selection problem and direct costs of bankruptcy. In such a framework good firms stick to debt to avoid the underpricing problem, signalling their better type and separating themselves from bad firms by their willingness to bear the risks of financial distress. ${ }^{8}$ However, once the setting is extended to include more effects it can be shown that the Myers-Majluf model is neither a necessary nor a sufficient condition for the pecking-order behaviour. On the one hand, Fulghieri and Larkin (2000) show that a Myers-Majluf setting can generate reversed pecking-order behaviour if information is endogenously generated. Firms may then choose to issue equity precisely because it is information sensitive and thus 
provides investors with an incentive to gather information about the firm. On the other hand, Fischer, Heinkel and Zechner (1989) demonstrate that a trade-off setting can generate pecking-order type of behaviour once a fixed cost per-issue of equity is introduced. Firms may then stray away from their target capital structure, adjusting leverage only when it passes a certain threshold, as in an Ss inventory theory. We return to this theory below.

In light of these theoretical difficulties, it is better to regard the pecking order as a descriptive proposition of observed patterns of financial behaviour, which may or may not be derived from a (modified) Myers-Majluf framework. Rejection of the conjecture is therefore not necessarily a rejection of the Myers-Majluf model, particularly not of the idea that debt and equity are used to signal firm quality. We narrow down our investigation to four testable propositions:

Proposition 1 (internal finance): According to the pecking-order conjecture, investment is mostly internally financed. Funds from current operations and accumulated reserves from previous periods should be fully utilized before any external finance is raised.

Proposition 2 (dominance of debt): According to the pecking-order theory, debt is the dominant form of external finance for high-quality firms, but the order may be reversed for low-quality firms. Firms tend to specialise in either debt or equity finance.

Proposition 3 (absence of a target): According to the pecking-order conjecture, even in the long run, (high quality) firms refrain from issuing equity so as to revert back to a certain "target leverage". Hence, leverage is just a buffer that passively absorbs cashflow shocks and drifts randomly without a target, unless the firm is sufficiently close to insolvency to be forced to issue equity.

Proposition 4 (lumpy equity issues): If firms face a per-issue fixed cost of raising equity, they use debt finance in the short run, undertaking equity adjustments in lumpy, infrequent issues. In such a world the pecking-order conjecture holds in the short run,

\footnotetext{
${ }^{8}$ See also Bolton and Freixas (2000) who describe a model in which both debt and equity are used in equilibrium.
} 
leverage reverts back to target in the longer run, and equity issues are lumpy and infrequent.

As already noted, our filter generates a dataset where investment events constitute a five-year string of firm-level investment data with a spike right in the middle, at "project-time zero". Propositions 1 and 2 can be tested cross-sectionally at project-time zero. Proposition 3 can be tested on a cross-section of five-year leverage disturbances and adjustments around project-time zero. It should be emphasised again that the leverage adjustments are associated with equity issues rather than the averaging out of cash flows over the long run. The lumpiness of equity issues in Proposition 4 can be analysed from the size and frequency of equity issues in the sample.

\section{Data and Methodology}

In this section we explain how our dataset was constructed. The "raw data" is described in Section 3.1, the filtering technique in Section 3.2, and the potential problem of selection bias in Section 3.3.

\subsection{The Raw Data}

Our raw data are flow-of-funds accounts of non-financial North American companies reported in Compustat for the years 1988-1998. All the companies are publicly traded, although some of them are not listed on an official exchange but rather "traded overthe-counter". The data have been deflated to constant prices using the consumer price index.

The raw data comprise more than eleven thousand companies. We have gone to considerable lengths to clean and check the data before using them. We performed several consistency checks - such as sources of funds equal uses of funds - and deleted records (company-years) that failed those tests. We also checked that firms have complete records, and deleted firms that failed to report key variables, such as after-tax income, depreciation, equity finance or debt-finance. Approximately four hundred companies were deleted as a consequence, leaving us with 10,667 companies.

Since our filter is conditional on having (at least) five uninterrupted records of data, it is interesting to note that there is a considerable turnover in Compustat. 
Although the raw data contains 10,667 companies, only 6,293 were still active in 1998 and only 4,253 were already active by $1988 ; 5,568$ had five consecutive records.

The next step is to aggregate the data into the following categories:

$$
I_{t, j}=\mathrm{OPR}_{t, j}+\text { EQUITY }_{t, j}+\mathrm{LTDEBT}_{t, j}+\mathrm{OTHER}_{t, j}
$$

where, $I$ is fixed investment,

OPR is cash flow from operations (after tax),

EQUITY is equity finance (net),

LTDEBT is long-term debt finance (net),

OTHER is the sum of all other variables,

$t$ is (calendar) time index and

$j$ is a company index.

As with all flow-of-funds accounts a positive (negative) sign on the right-hand-side means a source of funds (use of funds); for example, LTDEBT is positive (negative) when the firm borrows (repays) debt. The data-appendix provides some additional information on the items included in each aggregate (with their Compustat labels).

Missing variables require careful treatment. Note that the consistency checks reported above ensure that all records add-up so that "missing" does not mean "unaccounted for". It means either "aggregated into some other item" in a nontractable manner, or a "zero" that was confused with a "missing" observation when the dataset was compiled. We have thus replaced a missing value with a zero within variables I, OPR, EQUITY and LTDEBT. For example, EQUITY is equal to SSTK+ PRSTKC (sale of equity and purchase of equity, see Appendix A). If both components are missing the whole record should have been deleted at a previous stage when records were checked for completeness. (Note again that we did not delete records where EQUITY was equal to zero, only where it was missing). If, however, only one of SSTK and PRSTKC is missing then the missing item has been replaced with zero, on the assumption that EQUITY is already reported on a net basis. Checking this procedure against a sample of the original reports of a random sample of companies has convinced us that the procedure is sound and that the amount of measurement error introduced is small.

All other items are aggregated into OTHER. This variable includes items such as "changes in liquid assets" as well as "measurement errors" and genuinely "other" items. In light of the numerical examples in Table 1, it would have been desirable to identify change in liquid assets separately. However, if we disaggregate to that level 
and apply the above cleaning procedures then we end up with a dataset that either is considerably smaller, or has many measurement errors (or both). The present level of aggregation is therefore a reasonable compromise between sample size and quality of data. Most importantly, the basic items (I, OPR, EQUITY and LTDEBT) are measured with minimal errors.

\subsection{The Filter}

The filter is designed to identify spikes in firms' investment activity. A spike fits (with some random error terms) the pattern

$$
(1,1,2 \text { or more, } 1,1) \text {, }
$$

where 1 represents the off-spike normalised base level of investment and 2 sets the minimum ratio of the spike to base-level investment. The filter scans the raw data, mapping each record to a number that measures the goodness of fit of investment-data around that record to the pattern (2). The records with the best fit are used as our "filtered dataset" on which tests are then performed.

We start by defining an additional time line - "project time" indexed $\tau$ - that runs parallel to calendar time index, $t$, such that for each record $\tau$ equals zero while that record is being considered as a "candidate for a spike". (Obviously, record $j, t$ is defined as $\tau=0$ when it is considered as a candidate for a spike, but as $\tau=-1$ when record $j, t+1$, is considered as a candidate for a spike. $)^{9}$

The next step is to scale the five investment-data-points around the candidate record. Defining the base level of investment

$$
b_{j, t}=\frac{I_{j, t-2}+I_{j, t-1}+I_{j, t+1}+I_{j, t+2}}{4},
$$

we deflate

$$
i_{j, t+j}=\frac{I_{j, t+\tau}}{b_{j, t}}, \quad \tau=-2, \ldots,+2 .
$$

We then calculate the sum of squared errors around the pattern (2):

$$
E R_{j, t}=\frac{\sqrt{\sum_{\tau=-2}^{2} u_{j, t+\tau}^{2}}}{5},
$$

\footnotetext{
${ }^{9}$ Strictly speaking, the project-time index should come with a subscript $j, t$ that would define at what record of the raw data the index is set to zero. That step is avoided for brevity, as it is clear that all the
} 
where the error-term $u$ is defined as

$$
u_{j, t+\tau}=\left\{\begin{array}{cl}
\min \left(0, i_{j, t+\tau}-2\right) & \text { if } \tau=0 \\
i_{j, t+\tau}-1 & \text { otherwise }
\end{array}, \quad \tau=-2, \ldots,+2 .\right.
$$

Note that since we define the spike as double or more the base level, Equation (6) defines a positive deviation from the pattern at $\tau=0$ as a perfect fit. Thus, the expression in equation (5) maps each record in the raw data (excluding the first two and last two records for each firm) to a number that measures the goodness-of-fit of the five years of investment around that record to the pattern (2).

We use an intuitive criterion to evaluate how good a fit is. ${ }^{10}$ In order to help us choose a threshold, we eyeball Figure 1 - which contains a sample of strings arranged in decreasing order of quality of fit, with the best fit (lowest $E R_{j, t}$ ) at the upper-left corner. Project time $\tau=-2, \ldots, 2$ is plotted on the horizontal axis, while investment (normalised by the base-level of investment) is plotted against the vertical axis; the spike is located at $\tau=0$. We choose 0.25 as the critical threshold.

\section{Insert Figure 1 here}

Finally, we delete 17 firms with extreme values; the exclusion criterion is described in the data appendix and in Table A1. (The appendix also provides an industry breakdown of the sample.) The result is a dataset with 535 large investment events, each event having five years of data with the spike right in the middle.

It is useful at this point to provide some additional information about the characteristics of the filtered sample; see Table 2. Firms are sorted, according to their base-level of investment, into three equal size groups. Total assets are on average $\$ 3$ billion for large firms and $\$ 25$ million for small ones. Firms are fast growers: between $4.7 \%$ and $5.9 \%$ per annum over the five-year period, and $4.8 \%$ and $6.4 \%$ over the two years to the investment spike. High-growth prospects are reflected in market-to-book ratios of an average of just under 2. Leverage ratios (debt over total assets) range from an average of $51 \%$ in the small firms to $59 \%$ in the large firms. The main differences between size groups relate to profit (after tax income before extraordinary items

\footnotetext{
calculations below are done from the point of view of the given record while it is considered as a candidate for a spike.

${ }^{10}$ The use of such "intuitive criteria" is inherent to filters; had there been a structural theory of the pattern, there would be no need to use a filter.
} 
normalised by base level investment) and cash flow volatility. While large and medium-sized firms are on average profitable, small firms are on average loss making. The cash flow of small firms is appreciably more volatile than that of medium-sized and large firms.

Insert Table 2 here

\subsection{The Potential Problem of Selection Bias}

The use of a truncated sample raises two important questions: the first relates to the efficiency of the inference ("why throw away data"?) and the second to the potential selection bias. We delay discussion of the first question to Section 4.2 below.

There are two points to be made about selection bias. First, all our reported inferences are conditional on a large investment event. In that respect, our analysis is no different from other event studies. For example, when a bid premium is reported for a sample of takeover targets, it is clear that it is conditional upon such an event occurring. Wider inferences about firm performance cannot be drawn. Likewise in our analysis we are reporting financing patterns conditional on large investment events, and we are careful to ensure that our theoretical hypotheses - as formulated in Section 2 above - are specified accordingly. There is no selection bias as long as no attempt is made to infer results about firms that are not undertaking large investments.

Second, we can test whether firms in our filtered dataset differ from the general Compustat population by estimating the probability of being filtered out as a function of firm's (within-firm average) characteristics. The result of such a probit regression is reported in Table 3 Panel A. On the basis of this, we reject the hypothesis that certain characteristics increase the likelihood of a company being filtered out. In particular, we reject the hypothesis that more mature firms (measured by size of assets or by NYSE listing) have a higher propensity to be filtered out (a problem that afflicts the Shyam-Sunder and Myers (1999) study). We also reject the hypothesis that the sample is biased in terms of industry composition.

The only significant variables are dummies that measure the number of consecutive observations available on firms, namely their "duration". As expected, the longer is the period for which a firm reports data, the more likely it is to record a large investment event. A by-product of these dummies is an estimation of the probability of 
an investment spike: it ranges from $2.4 \%$ for a firm with five years of consecutive observations to $16.6 \%$ for a firm with 11 years of consecutive observations (see Panel B of Table 3). As noted above, investment spikes are not very frequent.

\section{Insert Table 3 here}

\section{Short Term Analysis}

This section considers Propositions 1 and 2 - the dominance of internal over external finance and of debt over equity in the short run during the investment spike. Section 4.1 presents the results of flow-of-funds analyses and regressions. Section 4.2 addresses the first part of the sample selection question raised in the previous section, "why throw away data?"

\subsection{Project Financing}

Table 4 describes flow-of-funds accounts deflated by base level of investment and aggregated in project time for the three size groups of firms defined above. The first point to observe is that the filter has clearly been successful at identifying large investment events. The average size of the investment spike is 2.71 times the base level of investment for large firms, 2.85 for medium-sized firms and 3.81 for small firms, where average investment off the spike equals 1 , by construction.

In contrast, cash flows are flat over time and much smaller than the spike; average funds from operations are 1.14 times the base level of investment for large firms, ${ }^{11} 1.26$ for medium-sized firms and only 0.58 for small firms. Hence, large and medium-sized firms have enough internal resources to fund all of their off-spike investment; indeed large firms do not raise much external finance from any source in non-spike years. In fact, firms repay debt in all non-spike years: on average, debt repayment is $8 \%$ of base-level investment in large firms, ${ }^{12} 8.5 \%$ among medium-sized companies and 56\% among small firms in non-spike years.

Insert Table 4 here

\footnotetext{
${ }^{11}$ Namely $5.69 / 5$.

${ }^{12}$ Namely, $(18+3+4+7) / 4$.
} 
While internal finance is the dominant source of funding off spike, it is much less important during the spike. ${ }^{13}$ The main source of finance for large and mediumsized firms during the investment spike is debt. It accounts for $60 \%$ of the incremental component of the investment spike for large firms, ${ }^{14}$ for $63 \%$ for medium-sized firms but for just $23 \%$ for small firms. For small firms, equity finance is the main source of external finance, accounting for $91 \%$ of the incremental investment in the spike year. In contrast, in medium-sized firms it amounts to just $11 \%$ and in large firms for a negligible percentage, which, as we will see below, actually buy-back substantial amounts of equity. In line with Chirinko and Singha (2000), the relationship between investment and funding is highly non-linear, with debt finance in particular heavily concentrated in years of large investments. It is also very dependent on the size of firms.

Clearly some of the investment spikes are associated with acquisitions and the financing of these might be expected to be different from that of other investments, possibly with a larger component of equity finance. In Panel B of Table 4 we examine the financing of acquisitions (defined as an expenditure on acquisitions of at least 0.5 base-level investment) ${ }^{15}$ separately from those of other investments. On this definition, $64 \%$ of investment spikes of large firms are attributable to acquisitions ${ }^{16}, 47 \%$ of medium-sized firms and $32 \%$ of small firms. However, the financing of acquisitions is very similar to that of the average investment spike: it is primarily debt for large and medium-sized firms and equity for small firms.

According to the pecking-order and Proposition 2, firms should specialise in either debt or equity finance. Figure 2 addresses this point. Debt finance (at $\tau=0$ ) is shown on the horizontal axis and new equity on the vertical axis, both deflated by the investment spike, so that the distance of an observation from the plotted diagonal measures the other sources used to finance the spike. There is a striking concentration of observations along the horizontal axis, particularly for large firms. According to

\footnotetext{
${ }^{13}$ It should be recalled that the variable "other" is an aggregation of several flows, including short-term funding and cash obtained from selling liquid assets. It could be argued, in line with the hypothetical firm B in Table 1, that liquidated assets are recently accumulated internal funds. As noted above, we choose not to disaggregate this variable for data-quality reasons but assuming that "other" is entirely attributable to accumulated funds then an upper bound can be put on internal funding during the investment spike of $37 \%$ (i.e. $0.63 /(2.71-1)$ ) for large firms and appreciably less than that for mediumsized and small firms.

${ }^{14}$ For large firms, 1.03 over 2.71-1.00.

${ }^{15}$ Assuming that base investment is internal rather than acquisitions, that means that, for an investment spike of 2 , at least $50 \%$ of the additional investment is associated with acquisitions.
} 
Panel B, 56\% of large firms do not issue any equity, where an "equity issue" is defined as a flow in excess of $10 \%$ of the base level of investment; only one large firm financed a large proportion of investment using equity finance. The number of equityspecialised firms increases as one moves towards the smaller size group: in small firms, $28 \%$ do not borrow a significant amount in the spike investment years but many raise large amounts of equity.

\section{Insert Figure 2 here}

On the assumption that small firms are on average of lower quality than other firms, the major role of equity finance in small firms is consistent with the peckingorder and Proposition 2. Table 5 provides further evidence on this. It records the flow of funds of firms engaging in substantial equity operations involving either a new equity issue or buy-back. A 'substantial' operation is one that is in excess of base level of investment, i.e. outside the range -1 to 1 times base-level investment, $b$. There are 297 substantial new equity issues in total over the period $\tau=-2$ to $+2,46$ by large firms, 64 by medium sized firms and 187 by small firms. There are 125 substantial buy-backs, 51 by large firms, 37 by medium sized firms and 37 by small firms. Therefore, while small firms issue equity around large investment projects, large firms engage in share buy-backs.

The new equity issue activity of small firms is associated with exceptionally large investment projects, 5.58 times base-level investment on average and large operating losses, -3.50 times base-level investment in the investment spike year. The buy-backs of large firms are associated with large operating profits (2.44 times baselevel investment) of a magnitude about equal to their spike investment (2.54 times base-level investment). New equity issues therefore primarily occur in small, loss making firms with large investment requirements and buy-backs in profitable, large firms. In line with previous observations, we also observe that equity issues in small firms are not confined to years of investment spikes - a large number occur either side of them.

Insert Table 5 here

\footnotetext{
${ }^{16} 115 / 179$.
} 
Table 6 reports more formal tests of Propositions 1 and 2. We regress both short-term debt and equity issuance during the investment spike $(\tau=0)$ on the size of the investment, cash flow from operations in $\tau=0$ and the "slack" accumulated over the two years prior to the spike (defined as cash flow minus investment cumulated over $\tau=-2$ and -1 ), all deflated by base level investment. ${ }^{17}$ Consistent with previous observations, the marginal propensity to borrow is about 0.6 of investment and highly significant in all firms - large, medium-sized and small. The investment coefficient in the debt regressions is therefore smaller than the unit value predicted by the pecking-order theory, as reported in Shyam-Sunder and Myers (1999) and Frank and Goyal (2003), but much greater than in the equity regressions where it is in general in the range 0.1 to 0.2 and sometimes insignificant.

\section{Insert Table 6 here}

The next four lines are a test of the prediction in the pecking-order and Proposition 1 that an additional dollar of internally generated funds decreases borrowing by a dollar; recently accumulated funds ("slack") should have a similar effect with firms utilizing accumulated resources before turning to external finance. This is clearly rejected: the coefficient on cash flow from "operations" is much smaller than unity and often insignificant. "Slack" performs even worse and frequently has the wrong sign. We then decompose cash flow from "operations" into positive (profits) and negative (losses) cash flows - labelled "operations \pm ". This reveals some striking results: there is a significant propensity to buy-back equity among large, profitable companies, and a strong tendency for small loss-making companies to raise new equity.

The next line checks whether the specification is sensitive to the initial level of leverage. Line 6 shows that, as predicted, firms with high initial leverage (i.e. $\tau=-2$ ) tend to borrow less and issue more equity, although the significance of some of the coefficients is low. The dynamics of leverage are examined in more detail in the next section so, at this stage, we merely note that the previous results are unaffected by the inclusion of leverage.

\footnotetext{
${ }^{17}$ Industry dummies have not been shown but their inclusion did not affect the results.
} 
The last line of table 6 reports the inclusion of expenditure on acquisitions in addition to total investment. In general the variable is insignificant ${ }^{18}$ rejecting the hypothesis that acquisitions are differently funded from other investment. The significance of the coefficient on investment is appreciably lower when acquisitions are included as a separate variable reflecting the fact that, by construction, total investment and acquisitions are highly correlated.

In summary, we reject proposition 1: large projects are largely financed from external sources and - contrary to Proposition 1 - firms do not exhaust all internal resources before they start raising external funds. However, the evidence is consistent with Proposition 2: debt dominates equity in the short run, particularly in large firms, even though the coefficient on investment is always less than unity. Profitable large firms buy equity back, and loss-making small firms issue equity.

\subsection{Funding Patterns: On Spike and Off Spike}

Section 3.3 recorded that the firms in our dataset do not have significantly different characteristics from a general population of Compustat firms. We also argue that as long as our estimates are properly interpreted as being conditional upon the incidence of a large investment event, there should be no concerns about selection bias. That, however, is not sufficient to justify our filtering approach for if the spike and the offspike relationships are similar (or the difference is easy to specify) then an estimate that retains all data and does not "throw some away" would be more efficient than one that does. We have mentioned some theoretical arguments why the relationship should be different on- and off-spikes (see Chirinko and Singha 2000 or the numerical examples in Table 1) and we have alluded to this in the discussion of the descriptive statistics above, but we have not so-far provided empirical evidence to support it.

Frank and Goyal (2003) make a related point. They argue that for the peckingorder to be regarded as the correct theory, it has not only to generate the right coefficients but also to outperform competing hypotheses. In that respect the peckingorder theory performs poorly: when nested jointly with the trade-off theory in a single specification, the coefficients of both theories remain statistically significant, and the pecking-order variables do not "wipe out the effects of the conventional variables". 19

\footnotetext{
${ }^{18}$ Except in medium sized firms where there is less equity financing of acquisitions on the margin than of other investment.

${ }^{19}$ See their Section 4.3.
} 
Furthermore, the pecking-order variables only modestly increase the regressions' Rsquared.

We extend this argument as follows. We show below in Section 5 that the pecking-order conjecture fails in the long run as firms rebalance their leverage. The pecking-order theory cannot therefore provide a comprehensive explanation of firms' behaviour at all times. Nevertheless, it is possible that borrowing dominates other financial activities during investment spikes. If this is the case, then pooling together data from the two regimes will dilute the sample and cloud results rather than increase the efficiency of the estimation.

In Table 7 we run two regressions, one on- and one off-spike (due to lags, the off-spike regression is restricted to project times -1 and 2). Panel A reports the results of a specification similar to that used in Table 6 . The difference in the investment coefficient - off- and on-spike - is striking. There is little explanatory power at all offspike but, as before, considerable explanatory power from investment expenditure onspike. Panel B reports a similar specification to the one used by Frank and Goyal $(2003) .^{20}$ In most cases, the trade-off coefficients have the same sign as in their analysis, although significance is much lower. More significantly, while investment the pecking-order variable - does not add much to their off-spike regressions, it almost eliminates the other variables on-spike and its marginal contribution to the R-squared is highly significant. There is therefore strong evidence of firms going through different regimes, in which the role of financing changes drastically.

\section{Long Term Analysis}

According to the pecking-order theory, firms abstain from issuing equity in the longas well as the short-run (see Proposition 3). As a result, leverage passively responds to cash-flow shortages and surpluses without tending to a target. Our dataset, with significant cash-shortage events and two-year adjustment periods either side, offers a convenient setting for testing this proposition. We also use it to evaluate two additional issues, which, to the best of our knowledge, have not been examined to date.

First, as Shyam-Sunder and Myers (1999) note, by itself leverage reversion cannot reject the pecking-order conjecture since it may result from cash shortages being averaged out over the long run (as the hypothetical examples in Table 1

\footnotetext{
${ }^{20}$ See their Table 7.
} 
illustrate). We are thus primarily interested in leverage adjustments that result from equity issues. For that purpose we define notional leverage (NOTNLEV) as the hypothetical leverage that a firm would have at project-time $\tau$ had all the external finance that it raised as equity (after $\tau=-2$ ) been raised in the form of debt. Hence,

$$
\operatorname{NOTNLEV}_{\tau}=\frac{\text { TOTALDEBT }_{\tau}+\sum_{i=-2}^{\tau} e q_{i}}{\text { TOTALASSETS }_{\tau}},
$$

where TOTALDEBT and TOTALASSETS are balance-sheet items ( $d t$ and $a t$ in Compustat notation, see Data Appendix) and eq is EQUITY (as in equation 1) deflated by the base-level of investment. In comparison, actual leverage is defined as TOTALDEBT / TOTALASSETS. Taking initial (i.e. $\tau=-2$ ) leverage as the target, the difference between initial actual and final (i.e. $\tau=+2$ ) notional leverage thus measures the potential disturbance to leverage: by how much leverage would have moved had the firm behaved according to the pecking-order conjecture and avoided equity finance altogether. The difference between the final-actual and the final-notional leverage is a measure of how much leverage adjustment occurs through issuing equity. The difference between actual-initial and the actual-final leverage is a measure of the actual change in leverage over the entire five-year period.

Second, we recognise that the pecking-order conjecture and the trade-off theory are observationally (and substantially) equivalent at high levels of leverage; with or without "financial managers' insomnia" high-leverage firms would issue equity in order to avoid insolvency. It follows that high-leverage firms do not provide a good basis for discriminating between theories. We thus refine our test by running partialadjustment regressions on a sequence of nested samples, where each sub-sample in turn eliminates the most highly leveraged firms from the previous one.

Figure 3 reports actual leverage against notional leverage (at $\tau=+2$ ). If actual leverage is smaller (larger) than notional leverage, i.e. lies below (above) the diagonal, then some equity has been issued (bought back). Consistent with previous observations, many firms do not issue any significant amounts of equity. There are more equity issues among small than large firms and high (low) leverage firms tend to issue (buy back) more equity. However, the concentration of points on the diagonal does not necessarily imply rejection of the trade-off theory since firms may abstain from issuing equity simply because the disturbances to their leverage have been smoothed out, thereby obviating the need to adjust leverage back to target. 


\section{Insert Figure 3 here}

Instead, in Figure 4 we show a partial-adjustment analysis by comparing notional with actual leverage changes over the entire five-year period. We measure leverage disturbance $\left(\mathrm{NOTNLEV}_{2}-\mathrm{LEV}_{-2}\right)$ on the horizontal axis and leverage adjustment $\left(\mathrm{LEV}_{2}-\mathrm{NOTNLEV}_{2}\right)$ on the vertical axis. If the partial-adjustment coefficient equals minus one, as shown in the reference diagonal, then final leverage reverts back to its initial level, which is the assumed target. If the partial adjustment parameter equals zero then final leverage equals notional, as predicted by the peckingorder theory. The figure shows a remarkable amount of reversion, particularly among large firms.

\section{Insert Figure 4 here}

Table 8 estimates the adjustment coefficient implied by Figure 4 . For the reasons explained above, we run the adjustment regressions on a sequence of samples where each sample is derived from the previous one by truncating firms with notional leverage above a certain threshold; the thresholds descend from 1 to 0.7 . We find that the reversion result is preserved in all sub-samples. Among large firms, the reversioncoefficient actually increases as the sample is truncated to lower leverage firms. $t$ statistics are much higher than in the short-run regression suggesting that since equity adjustments are erratic in size and in timing, averaging over a five-year window eliminates much of the noise and improves the quality of inference. Note also that the reversion coefficient is higher for large than small firms. Hence, the very size category of firms which performed best in terms of the pecking-order in the short run provides the strongest rejection of the theory in the long run.

\section{Insert Table 8 here}

In summary, Proposition 3 is flatly rejected. Not only do we find strong evidence of leverage reversion, we observe firms reverting by issuing equity and doing so even when they are well away from insolvency. 


\section{Size and Frequency of New Equity Issues}

The strong performance of the pecking-order in the short run, combined with its clear rejection in the long run, lead straight to Proposition 4: with fixed costs of issuing equity, firms lump equity issues together and make them once leverage crosses a certain threshold, as in Ss inventory theory (see Fischer, Heinkel and Zechner (1989)). In such a world, the pecking order would hold in the short run, but leverage would revert to a target in the longer run.

This theory implies that equity issues should be large and infrequent. We can transform this statement into three testable hypotheses. First, equity issues should display a bimodal size distribution with few small issues and many large ones of both positive and negative signs. Second, there should only be a small number of issues per firm. Third, if a company issues equity several times, it is because it has crossed the threshold several times, in which case the accumulated amount issued (over $\tau=-2, \ldots, 2$ ) should be large relative to a firm that has made few issues.

Testing these hypotheses raises the question of whether any non-zero observation should be counted as an equity issue or whether very small issues should be excluded. We have opted for the latter, firstly because there may be some issues associated, for example, with managers' stock options that are not relevant to this analysis and, secondly, because by including small issues we are making rejection of Proposition 4 too easy. Rejection after exclusion of small issues would be a much stronger result. We therefore classify 872 equity issues in the range $\pm 10 \%$ of the baselevel of investment as "non issues".

Figure 5 shows the size-distribution of equity issues, excluding the small issues as defined above and some additional 581 actual zeroes. A fitted normal distribution is plotted for reference. It shows a sizeable mass in the centre of the distribution, around zero. The formal tests in the panel below are consistent with the existence of kurtosis in all three size groups.

\section{Insert Figure 5 here}

Table 9 reports the distribution of the number of equity issues per firm, between 0 and 5 . Nearly $20 \%$ of firms do not issue any equity over the entire five-year 
period but between $21 \%$ and $35 \%$ issue equity four or five times. Many firms, both small and large ones, issue equity very frequently.

The next columns report a further test. If firms adjust leverage in lumpy equity issues then those that have made several issues must have crossed the threshold more often than others. The aggregate amount that they have issued over the entire five year period from $\tau=-2$ to +2 must be higher than those that make relatively few issues. The second column in Table 9 shows the aggregate amount of equity issued, while the third column aggregates equity issues in absolute terms to account for the possibility of hitting both the upper and lower threshold and engaging in both issues and buy-backs within the period. Table 9 tests the hypothesis that firms which issue equity once, twice, three or four times end up issuing the same aggregate amount of equity cannot be rejected at the $95 \%$ confidence level in large firms.

\section{Insert Table 9 here}

We therefore observe many firms issuing small amounts of equity frequently. High-frequency issuers do not seem to raise - over the entire five-year period - a larger amount relative to infrequent issuers, which could explain why they issue equity so many times. In summary, although the first part of Proposition $4-\mathrm{debt}$ in the short run with leverage reversion in the long run through equity issuance - is consistent with the data, the second part - that equity is issued infrequently and in large lumps - is not. As Leary and Roberts (2004) report, adjustment costs are more complex than the fixed cost form implied by the Fischer, Heinkel and Zechner (1989) model.

\section{Conclusions}

This paper reports a new approach to evaluating capital structure and the financing of investment. It describes a method of filtering large investment events out of the general Compustat population. There are several reasons why restricting attention to this sample is highly informative. First, most theory is developed for large and indivisible projects and it should be tested on corresponding data. Second, large investment events are interesting in their own right since much investment is executed in lumps. Third, if firms switch regimes, for example from normal periods to investment spikes and back to normal periods, and the patterns of finance differ across 
the regimes, then pooling data across regimes undermines the power of tests on capital structure. In addition, we have shown that the filtered sub-sample does not have different characteristics from the general population of firms and we have noted that, as long as estimates are interpreted as being conditional upon large investment events, then there is no selection bias. The filter therefore generates particularly informative not biased samples.

There are four major findings that emerge from the filter. First, although internal finance is the major source of funding off spike, it plays a relatively minor role in funding large investment events. Second, while this first result is inconsistent with the pecking order, in other respects, the pecking-order theory works quite well in the short run: debt dominates equity, particularly for large and profitable firms, many firms specialise in issuing either debt or equity, equity issuers tend to under-perform relative to the general population, and firms that buy-back equity tend to perform better than the general population. Third, we find strong evidence that firms revert back to their initial leverage. Our test is more refined than others in the literature in demonstrating that reversion is achieved by issuing equity, rather than through leverage disturbances simply averaging out in the long run. Furthermore, we demonstrate that reversion occurs even in cases where firms are well away from insolvency. This is important because the pecking order and trade-off theories are observationally equivalent for highly geared companies. Fourth, the second and third results cannot be interpreted as an attempt by firms to postpone equity adjustments to the point at which they hit certain thresholds since we find no evidence that equity issues are lumpy and infrequent.

In summary, the leading theories of capital structure can explain some but not all aspects of the data and no single theory is an adequate description on its own. Reality is more complicated than even the most-sophisticated and up-to-date theories suggest but hopefully the empirical insights provided by the methodology employed in this paper will assist in the development of new more sophisticated theories in the future. 


\section{References}

Allen, Franklin and Douglas Gale (2000). Comparing Financial Systems, Cambridge, Massachusetts: MIT Press.

Baker, M. and J. Wurgler (2002). "Market timing and capital structure", Journal of Finance, 57, pp. $1-32$.

Bradley, M, G. Jarrell and E. Kim (1984). "On the existence of an optimal capital structure: Theory and evidence”, Journal of Finance, 39, pp. $857-878$.

Brealey, R. A. and S. C. Myers (2000). Principles of Corporate Finance, $6^{\text {th }}$ edition, Boston: Irwin, McGraw-Hill.

Chirinko, R. and A. Singha (2000). "Testing static tradeoff against pecking order models of capital structure: A critical comment", Journal of Financial Economics, 58, pp. $417-425$.

Corbett, J. and T. Jenkinson (1997). "How is investment financed? A study of Germany, Japan, the United Kingdom and the United States", Manchester School, 65, pp. $69-93$.

Doms, M. and T. Dunne (1998). "Capital adjustment patterns in manufacturing plants," Review of Economic Dynamics, 1, pp. 409 - 429.

Fama, E. and K. French (2002). "Testing trade-off and pecking order theories predictions about dividends and debt", Review of Financial Studies, 15, pp. 134.

Fischer, E. R. Heinkel and J. Zechner (1989). "Dynamic capital structure choice: Theory and tests", Journal of Finance, 44, pp. 19 - 40.

Frank, M. and V. Goyal (2003). "Testing the pecking order theory of capital structure", Journal of Financial Economics, 67, pp. 217-248.

Goldberger, Arthur S (1991). A Course in Econometrics, Cambridge Massachusetts: Harvard University Press.

Harris, M. and A. Raviv (1991). "Theory of capital structure", Journal of Finance, 46, pp. $297-355$.

Leary, M. and M. Roberts (2004), "Do firms rebalance their capital structures?", mimeo, Fuqua School of Business, Duke University.

Mayer, C. (1988). "New issues in corporate finance", European Economic Review, 32, pp. $1167-1189$.

Myers, S. (1984). “The capital structure puzzle”, Journal of Finance, 39, pp. 575 592. 
Myers, S. and N. Majluf (1984). "Corporate financing and investment decisions when firms have information investors do not have", Journal of Financial Economics, 13, pp. $187-221$.

Rajan, R. and L. Zingales (1995). "What do we know about capital structure? Some evidence from international data", Journal of Finance, 50, pp. $1421-1460$.

Shyam-Sunder, L. and S. Myers (1999). "Testing static tradeoff against pecking order models of capital structure", Journal of Financial Economics, 51, pp. 219 244.

Stein, J. C. (1992). "Convertible bonds as backdoor equity financing", Journal of Financial Economics, 32, pp. 3 - 22.

Strabulaev, I. A. (2003). "Do tests of capital structure theory mean what they say?" mimeo, London Business School.

Titman, S. and R. Wessels (1988). "The determinants of capital structure choice", Journal of Finance, 43, pp. pp. 1 - 19.

Welch, I. (2004). "Capital structure and stock returns", Journal of Political Economy, 112, pp. 106-131. 


\section{Table 1}

The Basic Intuition - A Numerical Example

The table shows the flow-of-funds of three hypothetical firms ( + is a source of fund, - is a use of funds). All three firms have to finance an investment of an equal amount (over three years). In the case of firms B and C investment comes in the form of a lumpy project, whereas in Firm A it is spread over time. Firm A is internally financed, from current cash flow; Firm B is internally financed but the cash has to be accumulated for two years prior to the investment, while Firm $\mathrm{C}$ is (largely) externally financed. However, aggregating across the three years (fourth column), the financing of the three firms looks identical.

\begin{tabular}{|c|c|c|c|c|c|c|c|c|c|c|c|c|}
\hline \multirow[b]{2}{*}{ Time } & \multicolumn{4}{|c|}{ Firm A } & \multicolumn{4}{|c|}{ Firm B } & \multicolumn{4}{|c|}{ Firm C } \\
\hline & 1 & 2 & 3 & Aggr. & 1 & 2 & 3 & Aggr. & 1 & 2 & 3 & Aggr. \\
\hline Investment & -50 & -50 & -50 & -150 & 0 & 0 & -150 & -150 & -150 & 0 & 0 & -150 \\
\hline Operations & +50 & +50 & +50 & +150 & +50 & +50 & +50 & +150 & +50 & +50 & +50 & +150 \\
\hline Liquid Assets & 0 & 0 & 0 & 0 & -50 & -50 & +100 & 0 & 0 & 0 & 0 & 0 \\
\hline External Fin. & 0 & 0 & 0 & 0 & 0 & 0 & 0 & 0 & +100 & -50 & -50 & 0 \\
\hline
\end{tabular}




\section{Figure 1}

\section{A Sample of Investment Strings with their Measure of Goodness of Fit}

The figure provides an illustration of the relationship between the ER measure of the goodness of fit (see equation (6)) and different investment strings. It plots investment normalised by base level investment (which equals 1 in the graphs) against project time. $\tau$ is the time index for 'project year' with the spike at $\tau=0$. We have sampled strings with ERs between 0.1 and 0.4 . at ticks of (approximately) 0.02 . The quality of fit is decreasing across strings (i.e. ER is increasing from upper-left to bottom-right).

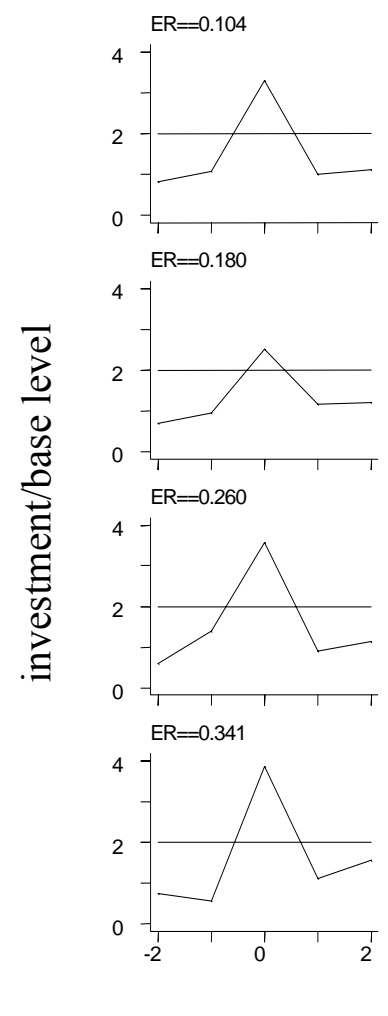

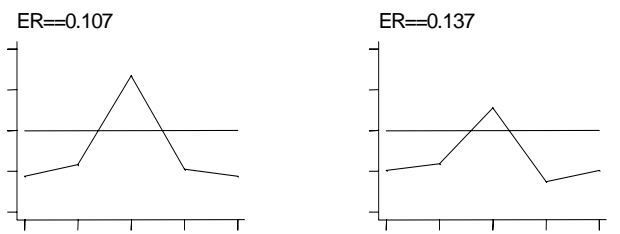

$\mathrm{ER}==0.199$

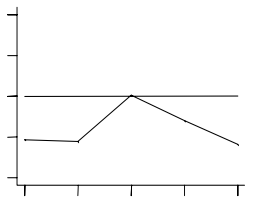

$E R==0.280$

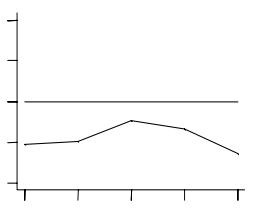

$E R=0.360$

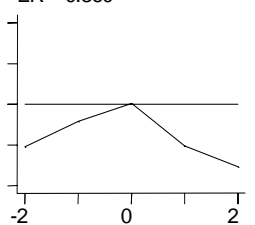

$E R=0.220$

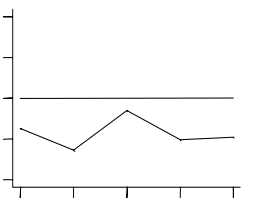

$E R==0.301$

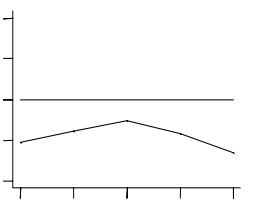

$E R=0.380$

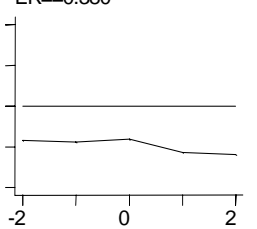

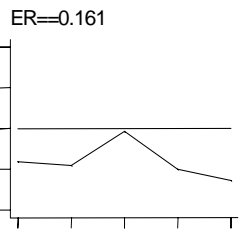

$E R==0.240$

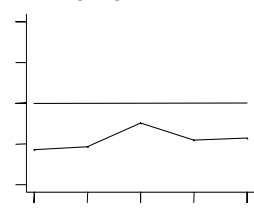

$E R=0.319$

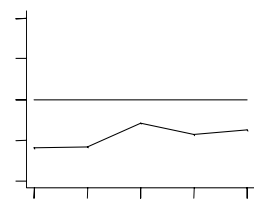

$E R=0.401$

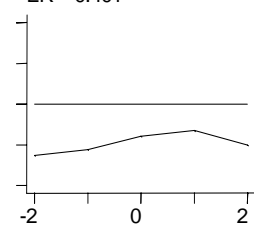


Table 2

Firm Characteristics By Size Groups

This table reports means and standard deviations (in brackets) of firm characteristics of the filtered sample of firms partitioned by three equal size groups (179 large, 178 medium and 178 small firms) determined by base level of investment $(b)$. The definitions of firm's characteristics are as follows:

Total assets are as defined in COMPUSTAT (see data appendix).

Growth: total assets, $\tau=-2$ to $\tau=2$, annualized.

Growth to spike: total assets, $\tau=-2$ to $\tau=0$, annualized over five years,

Market/book: (total liabilities + market value of equity)/ book value of assets (at $\tau=-2$ ).

Profit: after tax income before extraordinary items/base level of investment.

Leverage (static): total debt/ total assets.

Cash-flow volatility: intra-firm standard deviation of cash flow (after tax) from operations

\begin{tabular}{lccc}
\hline Size-Group & Large & Medium & Small \\
\hline Total Assets (\$ million) ( $\tau=-2)$ & $3,061(6,188)$ & $144(114)$ & $25(29)$ \\
Growth (\%) & $4.7(8.4)$ & $5.9(10.6)$ & $5.2(12.7)$ \\
Growth to Spike (\%) & $4.8(6.4)$ & $5.9(8.4)$ & $6.4(11.4)$ \\
Market/Book ( $\tau=-2)$ & $1.92(1.34)$ & $1.83(1.28)$ & $1.94(1.53)$ \\
Market/Book ( $\tau=2)$ & $1.93(1.26)$ & $1.57(0.80)$ & $1.75(1.43)$ \\
Profit & $0.67(1.24)$ & $0.60(1.66)$ & $-0.75(4.45)$ \\
Leverage $(\tau=-2)$ & $0.59(0.22)$ & $0.52(0.24)$ & $0.51(0.29)$ \\
Cash-Flow Volatility & $0.57(0.76)$ & $1.04(1.55)$ & $3.10(3.48)$ \\
\hline
\end{tabular}




\section{Table 3}

\section{Testing for Selection Bias}

In Panel A, we look for systematic differences between the raw data and the filtered dataset. 'Mean' refers to averages of company means. In the last column we report the results of a probit regression where the dependent variable takes a value of one if the firm is filtered out, and zero if it is not (z-statistics in brackets). The regression is run on the raw COMPUSTAT data; each record containing a vector of firm's average characteristics.

Panel B presents the probability of being filtered out as a function of duration, estimated from a probit regression using a separate dummy variable for all possible durations (of five to eleven years). "Duration" refers to the number of consecutive observations available for each firm. No other variables are included. Regression coefficients (z-statistics) are reported.

\section{Panel A}

Relation Between Raw Panel and Filtered Sample

\begin{tabular}{lcccc}
\hline & \multicolumn{3}{c}{ Mean } & Probit \\
\cline { 2 - 3 } \cline { 2 - 3 } Total Assets (\$m) & Raw data & Filtered dataset & \\
Earning/ Assets & 776.55 & 1174.23 & $-0.00(-0.50)$ \\
Market-Book Ratio & 0.09 & 0.06 & $0.22(1.49)$ \\
Debt/Asset & 2.52 & 1.89 & $-0.00(-0.07)$ \\
Industry Dummies & 0.61 & 0.54 & $-0.05(-0.41)$ \\
Duration Dummies & & & Insignificant \\
& & Incidence & & Significant \\
NYSE & 1817 & 215 & $0.21(1.05)$ \\
AMEX & 480 & 35 & $-0.07(-0.35)$ \\
NASDAQ & 4882 & 249 & $0.05(0.24)$ \\
OTHER & 364 & 21 & \\
N & 7543 & 510 & \\
$\mathbf{R}^{2}$ & & & \\
\hline
\end{tabular}

\section{Panel B}

Probability of Being Filtered Out, Conditional on Duration

\begin{tabular}{lcc}
\hline \multicolumn{1}{c}{ Duration Dummies } & Coefficient & Conditional Probability (\%) \\
\hline $\mathbf{5}$ years & $4.15(25.99)$ & 2.39 \\
$\mathbf{6}$ years & $4.27()$. & 3.22 \\
$\mathbf{7}$ years & $4.64(32.24)$ & 6.94 \\
$\mathbf{8}$ years & $4.63(30.07)$ & 6.68 \\
$\mathbf{9}$ years & $4.79(34.28)$ & 9.18 \\
$\mathbf{1 0}$ years & $4.94(37.53)$ & 11.9 \\
$\mathbf{1 1}$ years & $5.15(43.57)$ & 16.6 \\
& & \\
$\mathbf{N}$ & 7543 & \\
$\mathbf{R}^{2}$ & 0.17 & \\
\hline
\end{tabular}




\section{Table 4}

\section{Flow of Funds for Filtered Sample}

Panel A presents flow of funds for the whole filtered sample (535 firms) by project year $\tau$ and for the five years $\tau=-2$ to 2 . All variables are deflated by the base level of investment, i.e. I, OPR, EQUITY LTDEBT and OTHER divided by $b$ as defined in equation (3). A “+” indicates a source of funds, a "." indicates a use of funds, so that all rows add-up, horizontally, to zero. Size is measured by $b$, and the sample is split into three groups with approximately the same number of observations in each. The table reports arithmetic means and standard deviations (in brackets) for each size group.

Panel B presents flow of funds for acquisitions only at $\tau=0$. A spike is defined as an acquisition if the expenditure on the acquisition (deflated by the base-level of investment) exceeded 0.5.

\section{Panel A: All Firms}

\begin{tabular}{|c|c|c|c|c|c|}
\hline$\tau$ & Investment & Operations & Equity & Debt & Other \\
\hline \multicolumn{6}{|c|}{ Large Firms (N=179) } \\
\hline-2 & $-0.96(0.18)$ & $1.00(0.92)$ & $0.18(1.00)$ & $-0.18(1.00)$ & $-0.03(1.52)$ \\
\hline-1 & $-1.00(0.17)$ & $1.20(0.86)$ & $-0.01(090)$ & $-0.03(1.97)$ & $-0.16(1.91)$ \\
\hline $\mathbf{0}$ & $-2.71(1.80)$ & $1.04(1.16)$ & $0.01(0.90)$ & $1.03(1.60)$ & $0.63(1.40)$ \\
\hline 1 & $-1.04(0.17)$ & $1.13(1.63)$ & $0.04(1.06)$ & $-0.04(1.30)$ & $-0.09(1.92)$ \\
\hline 2 & $-0.99(0.17$ & $1.33(1.23)$ & $-0.32(1.08)$ & $-0.07(0.81)$ & $0.05(1.16)$ \\
\hline Total & $-6.71(1.80)$ & $5.69(4.24)$ & $-0.09(3.25)$ & $0.72(3.26)$ & $0.40(4.57)$ \\
\hline \multicolumn{6}{|c|}{ Medium-Sized Firms (N=178) } \\
\hline-2 & $-0.94(0.18)$ & $1.02(2.82)$ & $0.52(2.29)$ & $-0.06(1.77)$ & $-0.54(3.55)$ \\
\hline-1 & $-1.03(0.20)$ & $1.39(1.51)$ & $0.41(1.86)$ & $-0.16(1.76)$ & $-0.61(2.07)$ \\
\hline $\mathbf{0}$ & $-2.85(2.45)$ & $1.36(2.25)$ & $0.20(1.10)$ & $1.17(2.52)$ & $0.12(2.97)$ \\
\hline 1 & $-1.05(0.20)$ & $1.25(2.01)$ & $0.07(1.54)$ & $-0.04(2.29)$ & $-0.23(2.82)$ \\
\hline 2 & $-0.98(0.20)$ & $1.27(2.72)$ & $0.01(2.30)$ & $-0.08(3.18)$ & $-0.22(4.02)$ \\
\hline Total & $-6.85(2.45)$ & $6.29(8.03)$ & $1.20(4.87)$ & $0.84(4.96)$ & $-1.48(8.59)$ \\
\hline \multicolumn{6}{|c|}{ Small Firms $(\mathrm{N}=178)$} \\
\hline-2 & $-0.96(0.21)$ & $0.85(4.68)$ & $2.06(6.13)$ & $-0.54(3.60)$ & $-1.41(6.71)$ \\
\hline-1 & $-1.03(0.21)$ & $1.20(5.45)$ & $2.57(6.66)$ & $-0.75(3.69)$ & $-1.98(7.23)$ \\
\hline $\mathbf{0}$ & $-3.81(4.69)$ & $0.78(5.90)$ & $2.56(7.53)$ & $0.64(4.84)$ & $-0.17(7.85)$ \\
\hline 1 & $-1.01(0.20)$ & $-0.07(6.59)$ & $0.59(3.98)$ & $-0.30(3.78)$ & $0.79(7.17)$ \\
\hline 2 & $-0.99(0.21)$ & $0.13(7.31)$ & $1.12(5.72)$ & $-0.65(3.58)$ & $0.39(7.57)$ \\
\hline Total & $-7.81(4.69)$ & $2.89(22.04)$ & $8.90(19.74)$ & $-1.60(9.00)$ & $-2.38(18.10)$ \\
\hline
\end{tabular}

Panel B: Acquisitions Only at $\tau=0$

\begin{tabular}{cccccc}
\hline $\begin{array}{c}\text { Acquisition } \\
\text { Investment }\end{array}$ & $\begin{array}{c}\text { 'Ordinary’ } \\
\text { Investment }\end{array}$ & Operations & Equity & Debt & Other \\
\hline \multicolumn{7}{c}{ Large Firms (115 acquisitions) } \\
$-2.18(2.08)$ & $-0.94(0.29)$ & $1.12(1.05)$ & $0.03(0.85)$ & $1.22(1.86)$ & $0.74(1.50)$ \\
Medium-Sized Firms (83 acquisitions) & \\
$-2.69(3.4)$ & $-1.00(0.44)$ & $1.53(1.55)$ & $0.21(1.16)$ & $1.69(3.32)$ & $0.25(3.06)$ \\
$-4.51(6.63)$ & $-1.35(0.86)$ & Small Firms (57 acquisitions) & \\
$-1.24(6.37)$ & $2.05(5.00)$ & $1.95(6.20)$ & $0.62(7.64)$ \\
\hline
\end{tabular}




\section{Figure 2}

\section{Sources of Finance at $\boldsymbol{l}=0$}

Panel A records the ratio of debt finance to investment in the year of the investment spike on the horizontal axis and the ratio of equity finance to investment on the vertical axis for the sample of firms partitioned into three equal size groups.

Panel B shows the incidence (as a percentage) of the exclusive use of debt or equity finance in period $\tau=0$. A firm is classified as having "no debt" if debt deflated by the base level of investment is smaller than 0.1 in absolute terms. A corresponding classification is used for equity

\section{Panel A: Sources of Finance}

equity/investment
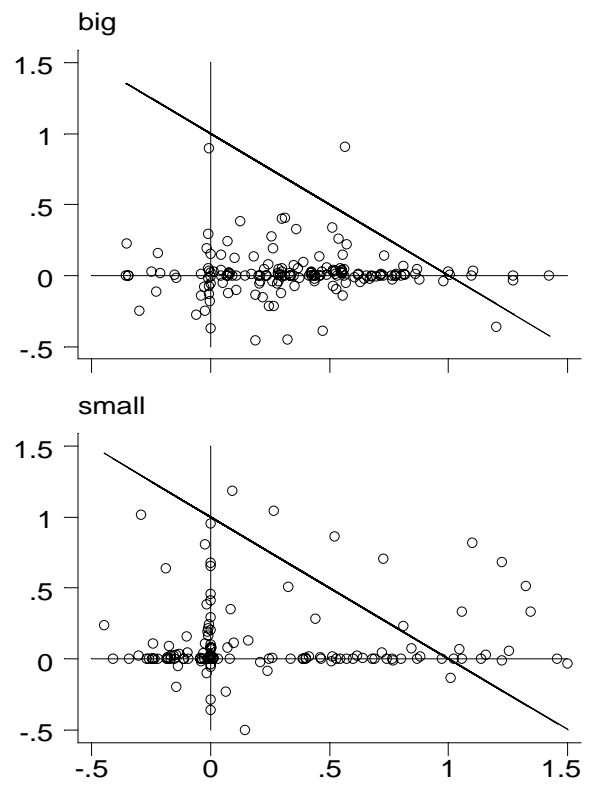

debt/investment

Graphs by size diagonal

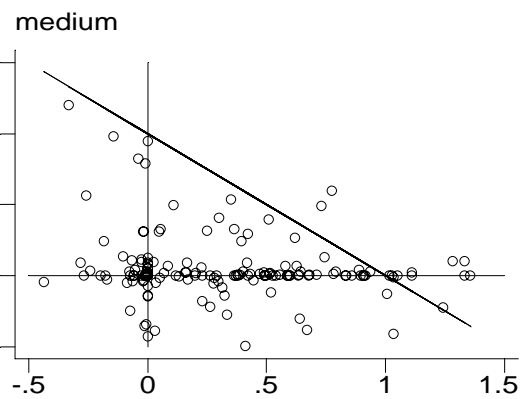

Panel B: Incidence of Exclusive Use of Debt or Equity Funding (\%)

\begin{tabular}{lccc}
\hline & Large Firms & Medium-sized Firms & Small Firms \\
\hline No debt & 12.30 & 21.91 & 27.53 \\
No equity & 56.42 & 53.37 & 48.31 \\
\hline
\end{tabular}


Table 5

Flow of Funds Around Substantial Equity Issues and Buy-Backs

This table records flow of funds (as a proportion of base level investment) for firms that have engaged in substantial equity operations - issues and buy-backs. A substantial operation is defined as one that falls outside of the segment $[-1,1]$, i.e. is more than base level investment $(b) . \mathrm{N}$ is the number of such issues and buy-backs. Figures in brackets are t-statistics.

\begin{tabular}{|c|c|c|c|c|c|c|}
\hline$\tau$ & $\mathbf{N}$ & Investment & Operations & Equity & Debt & Other \\
\hline \multicolumn{7}{|c|}{ Large Firms (N=179) } \\
\hline \multicolumn{7}{|c|}{ Equity Issues } \\
\hline$-1,-2$ & 24 & $-0.92(0.21)$ & $0.70(0.67)$ & $2.41(2.08)$ & $-0.97(2.15)$ & $-1.22(2.10)$ \\
\hline $\mathbf{0}$ & 8 & $-3.06(2.25)$ & $-1.11(3.00)$ & $2.45(1.64)$ & $-0.24(1.84)$ & $1.95(2.84)$ \\
\hline 1,2 & 14 & $-1.07(0.15)$ & $0.85(1.05)$ & $2.41(1.31)$ & $-1.16(1.91)$ & $-1.04(1.32)$ \\
\hline \multicolumn{7}{|c|}{ Buy-Backs } \\
\hline$-1,-2$ & 15 & $-1.00(0.15)$ & $2.12(1.53)$ & $-1.82(0.99)$ & $0.24(0.98)$ & $0.46(1.08)$ \\
\hline 0 & 7 & $-2.54(1.23)$ & $2.44(1.79)$ & $-2.62(1.75)$ & $1.63(2.42)$ & $1.08(1.51)$ \\
\hline 1,2 & 29 & $-1.02(0.16)$ & $2.90(1.76)$ & $-2.62(1.88)$ & $0.51(1.46)$ & $0.24(1.71)$ \\
\hline \multicolumn{7}{|c|}{ Medium-Size Firms (N=178) } \\
\hline \multicolumn{7}{|c|}{ Equity Issues } \\
\hline$-1,-2$ & 29 & $-1.07(0.20)$ & $1.14(1.51)$ & $4.52(4.54)$ & $-1.86(3.05)$ & $-2.73(3.50)$ \\
\hline 0 & 17 & $-4.90(6.20)$ & $1.06(1.27)$ & $2.73(1.65)$ & $1.34(4.36)$ & $-0.23(1.68)$ \\
\hline 1,2 & 18 & $-1.02(0.23)$ & $1.57(6.74)$ & $4.81(3.22)$ & $-2.26(4.77)$ & $-3.10(8.71)$ \\
\hline \multicolumn{7}{|c|}{ Buy-Backs } \\
\hline$-1,-2$ & 8 & $-1.06(0.18)$ & $1.72(0.77)$ & $-1.72(40.5)$ & $0.82(1.24)$ & $0.25(1.25)$ \\
\hline 0 & 5 & $-2.71(1.13)$ & $2.18(0.65)$ & $-2.16(1.89)$ & $0.08(0.21)$ & $2.61(1.81)$ \\
\hline 1,2 & 24 & $-1.05(0.18)$ & $2.39(2.07)$ & $-3.44(4.52)$ & $1.03(4.87)$ & $1.06(2.28)$ \\
\hline \multicolumn{7}{|c|}{ Small Firms (N=178) } \\
\hline \multicolumn{7}{|c|}{ Equity Issues } \\
\hline$-1,-2$ & 91 & $-1.03(0.23)$ & $-0.20(6.10)$ & $9.63(9.23)$ & $-1.35(4.35)$ & $-7.04(8.02)$ \\
\hline 0 & 42 & $-5.58(7.07)$ & $-3.50(9.06)$ & $10.89(12.3)$ & $2.20(7.13)$ & $-4.01(11.7)$ \\
\hline 1,2 & 54 & $-1.01(0.23)$ & $-2.83(9.11)$ & $6.97(9.51)$ & $-0.89(4.13)$ & $-2.24(11.0)$ \\
\hline \multicolumn{7}{|c|}{ Buy-Backs } \\
\hline$-1,-2$ & 14 & $-1.04(0.18)$ & $1.61(4.65)$ & $-3.91(2.99)$ & $1.10(3.46)$ & $2.24(6.62)$ \\
\hline 0 & 6 & $-3.07(2.08)$ & $1.63(6.32)$ & $-1.95(0.54)$ & $0.30(3.15)$ & $3.09(6.53)$ \\
\hline 1,2 & 17 & $-1.01(0.22)$ & $3.70(9.56)$ & $-5.20(7.75)$ & $-1.93(5.42)$ & $4.44(8.40)$ \\
\hline
\end{tabular}


Table 6

\section{Regression of Project Finance $(\tau=\mathbf{0})$ on Investment and Earnings}

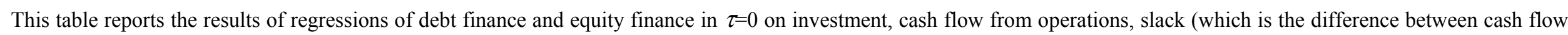

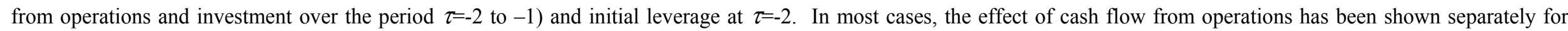

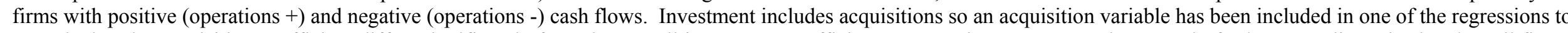

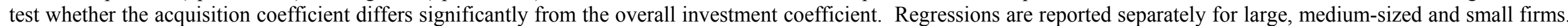
$\mathrm{t}$-statistics are shown in brackets.

\begin{tabular}{ccccccccc}
\hline & \multicolumn{7}{c}{ Large Firms (N=179) } \\
\cline { 2 - 9 } & \multicolumn{7}{c}{ Debt Financing } & \multicolumn{7}{c}{ Equity Financing } \\
\hline Investment & 0.59 & 0.60 & 0.60 & 0.56 & 0.08 & 0.08 & 0.08 & 0.02 \\
& $(11.54)$ & $(12.02)$ & $(11.97)$ & $(3.83)$ & $(2.42)$ & $(2.57)$ & $(2.52)$ & $(0.23)$ \\
Operations & -0.19 & & & & -0.22 & & & \\
& $(-1.87)$ & & & & $(-3.52)$ & & & \\
Slack & 0.09 & 0.16 & 0.16 & 0.16 & -0.17 & -0.15 & -0.14 & -0.14 \\
& $(1.32)$ & $(2.12)$ & $(2.17)$ & $(2.15)$ & $(-3.77)$ & $(-3.20)$ & $(-2.87)$ & $(-2.90)$ \\
Operations & & -0.50 & -0.51 & -0.51 & & -0.33 & -0.34 & -0.34 \\
& & $(-3.45)$ & $(-3.47)$ & $(-3.43)$ & & $(-3.47)$ & $(-3.58)$ & $(-3.51)$ \\
Operations - & & 0.09 & 0.11 & 0.11 & & -0.13 & -0.09 & -0.10 \\
& & $(0.66)$ & $(0.78)$ & $(0.77)$ & & $(-1.48)$ & $(-1.02)$ & $(-1.04)$ \\
Initial leverage & & & -0.22 & -0.23 & & & 0.36 & 0.37 \\
& & & $(-0.50)$ & $(-0.51)$ & & & $(1.28)$ & $(1.31)$ \\
Acquisitions & & & & 0.04 & & & 0.06 \\
& & & & & $(-0.28)$ & & & $(0.68)$ \\
$\mathbf{R}^{2}$ & 0.44 & 0.47 & 0.47 & 0.47 & 0.28 & 0.29 & 0.30 & 0.30 \\
\hline
\end{tabular}


Table 6: cont.

\section{Medium-Sized Firms (N=178)}

\begin{tabular}{|c|c|c|c|c|c|c|c|c|}
\hline \multirow{4}{*}{ Investment } & \multirow{2}{*}{\multicolumn{4}{|c|}{ Debt Financing }} & \multirow{2}{*}{\multicolumn{4}{|c|}{ Equity Financing }} \\
\hline & & & & & & & & \\
\hline & 0.66 & 0.66 & 0.66 & 0.87 & 0.21 & 0.21 & 0.20 & 0.39 \\
\hline & $(10.98)$ & $(10.94)$ & $(10.93)$ & $(4.29)$ & $(7.03)$ & $(7.01)$ & $(7.02)$ & $(4.03)$ \\
\hline \multirow[t]{2}{*}{ Operations } & -0.02 & & & & -0.01 & & & \\
\hline & $(-0.31)$ & & & & $(-0.40)$ & & & \\
\hline \multirow[t]{2}{*}{ Slack } & 0.00 & 0.01 & -0.00 & -0.00 & -0.04 & -0.03 & -0.01 & -0.01 \\
\hline & $(0.10)$ & $(0.17)$ & $(-0.03)$ & $(0.03)$ & $(-1.82)$ & $(-1.66)$ & $(-0.58)$ & $(-0.48)$ \\
\hline \multirow[t]{2}{*}{ Operations + } & & -0.07 & -0.07 & -0.08 & & -0.06 & -0.06 & -0.07 \\
\hline & & $(-0.58)$ & $(-0.58)$ & $(-0.63)$ & & $(-1.08)$ & $(-1.11)$ & $(-1.22)$ \\
\hline \multirow{2}{*}{ Operations - } & & 0.01 & 0.01 & 0.02 & & 0.02 & 0.02 & 0.02 \\
\hline & & $(0.12)$ & $(0.13)$ & $(0.17)$ & & $(0.44)$ & $(0.53)$ & $(0.52)$ \\
\hline \multirow[t]{2}{*}{ Initial leverage } & & & -0.38 & -0.39 & & & 1.01 & 1.01 \\
\hline & & & $(-0.59)$ & $(-0.60)$ & & & $(3.29)$ & $(3.30)$ \\
\hline \multirow{2}{*}{ Acquisitions } & & & & -0.20 & & & & -0.18 \\
\hline & & & & $(-1.08)$ & & & & $(-2.01)$ \\
\hline \multirow[t]{3}{*}{$\mathbf{R}^{2}$} & 0.41 & 0.41 & 0.41 & 0.42 & 0.23 & 0.24 & 0.28 & 0.30 \\
\hline & \multicolumn{8}{|c|}{ Small Firms (N=178) } \\
\hline & \multicolumn{4}{|c|}{ Debt Financing } & \multicolumn{4}{|c|}{ Equity Financing } \\
\hline \multirow[t]{2}{*}{ Investment } & 0.58 & 0.60 & 0.60 & 0.47 & 0.18 & 0.12 & 0.13 & -0.13 \\
\hline & $(8.96)$ & $(9.35)$ & $(9.36)$ & $(3.88)$ & $(1.69)$ & $(1.19)$ & $(1.21)$ & $(-0.66)$ \\
\hline \multirow[t]{2}{*}{ Operations } & -0.08 & & & & -0.58 & & & \\
\hline & $(-1.33)$ & & & & $(-5.56)$ & & & \\
\hline \multirow[t]{2}{*}{ Slack } & 0.07 & 0.09 & 0.07 & 0.07 & -0.05 & -0.08 & -0.06 & -0.07 \\
\hline & $(1.81)$ & $(2.14)$ & $(1.73)$ & $(1.61)$ & $(-0.75)$ & $(-1.19)$ & $(-0.81)$ & $(-0.95)$ \\
\hline \multirow[t]{2}{*}{ Operations + } & & -0.34 & -0.33 & -0.30 & & -0.02 & -0.04 & 0.00 \\
\hline & & $(-2.78)$ & $(-2.64)$ & $(-2.42)$ & & $(-0.09)$ & $(-0.22)$ & $(0.02)$ \\
\hline \multirow[t]{2}{*}{ Operations - } & & 0.03 & 0.04 & 0.02 & & -0.83 & -0.84 & -0.88 \\
\hline & & $(0.40)$ & $(0.50)$ & $(0.28)$ & & $(-6.50)$ & $(-6.59)$ & $(-6.78)$ \\
\hline \multirow[t]{2}{*}{ Initial leverage } & & & -1.37 & -1.53 & & & 2.18 & 1.85 \\
\hline & & & $(-1.32)$ & $(-1.46)$ & & & $(1.29)$ & (1.09) \\
\hline \multirow[t]{2}{*}{ Acquisitions } & & & & -0.16 & & & & 0.33 \\
\hline & & & & $(1.20)$ & & & & $(1.52)$ \\
\hline $\mathbf{R}^{2}$ & 0.34 & 0.36 & 0.37 & 0.37 & 0.25 & 0.30 & 0.30 & 0.31 \\
\hline
\end{tabular}


Table 7

Debt Regressions During the Spike $(\tau=0)$ and Off Spike $(\tau=-1, \tau=2)$ on Investment and Earnings

This table compares the results of debt regressions during the spike $(\tau=0)$ and off spike $(\tau=-1, \tau=2)$. The dependent variable is debt finance, deflated by the base-level of investment. Panel A reports a basic specification similar to that of Table 6. Panel B reports a specification augmented with some additional variables, close in spirit to Table 7 in Frank and Goyal (2003). "Tangibility" is (fixed assets)/(total assets), "profitability" is (after tax income before extraordinary items)/(total assets), "leverage" is (total debt)/(total assets) and "lagged" means a one-period lag. See the data appendix for COMPUSTAT labels. t-statistics are shown in brackets.

\begin{tabular}{|c|c|c|c|c|c|c|}
\hline & \multicolumn{2}{|c|}{ Large Firms } & \multicolumn{2}{|c|}{ Medium-Sized Firms } & \multicolumn{2}{|c|}{ Small Firms } \\
\hline & Off Spike & Spike & Off Spike & Spike & Off Spike & Spike \\
\hline & \multicolumn{6}{|c|}{ Panel A: Basic Specification } \\
\hline Investment & 0.24 & 0.59 & 1.26 & 0.66 & 1.30 & 0.59 \\
\hline & $(0.51)$ & $(11.60)$ & $(1.84)$ & $(11.02)$ & $(1.42)$ & $(9.17)$ \\
\hline \multirow{2}{*}{ Operations } & -0.11 & -0.12 & -0.01 & -0.02 & -0.12 & -0.02 \\
\hline & $(-1.40)$ & $(-1.42)$ & $(-0.01)$ & $(-0.35)$ & $(-4.01)$ & $(-0.37)$ \\
\hline \multirow[t]{2}{*}{ Initial Leverage } & 0.29 & -0.20 & -0.54 & -0.36 & -0.28 & -1.85 \\
\hline & $(0.76)$ & $(-0.46)$ & $(-1.15)$ & $(-0.59)$ & $(-0.43)$ & $(-1.81)$ \\
\hline $\mathbf{N}$ & 358 & 179 & 356 & 178 & 355 & 178 \\
\hline \multirow[t]{2}{*}{$\mathbf{R}^{2}$} & 0.01 & 0.44 & 0.01 & 0.41 & 0.05 & 0.34 \\
\hline & \multicolumn{6}{|c|}{ Panel B: Augmented Specification } \\
\hline \multirow[t]{2}{*}{ Investment } & 0.05 & 0.59 & 1.40 & 0.66 & 0.97 & 0.59 \\
\hline & $(0.05)$ & $(11.22)$ & $(2.05)$ & $(10.91)$ & $(1.07)$ & $(9.24)$ \\
\hline \multirow{2}{*}{ Tangibility } & -0.01 & -0.04 & 0.35 & 0.25 & 1.48 & 0.93 \\
\hline & $(-0.06)$ & $(0.13)$ & $(0.82)$ & $(0.55)$ & $(2.13)$ & $(0.88)$ \\
\hline \multirow[t]{2}{*}{ Profitability } & -1.01 & -0.84 & -1.21 & -0.35 & -1.93 & 0.70 \\
\hline & $(-0.94)$ & $(-0.61)$ & $(-1.43)$ & $(-0.36)$ & $(-2.53)$ & $(0.38)$ \\
\hline \multirow[t]{2}{*}{ Lagged Leverage } & -1.11 & -0.29 & -1.12 & 0.38 & -2.62 & -2.94 \\
\hline & $(-2.86)$ & $(-0.64)$ & $(-2.01)$ & $(0.53)$ & $(-3.98)$ & $(-2.62)$ \\
\hline $\mathbf{N}$ & 358 & 179 & 356 & 178 & 356 & 178 \\
\hline $\mathbf{R}^{2}$ & 0.02 & 0.43 & 0.03 & 0.41 & 0.07 & 0.35 \\
\hline $\mathbf{R}^{2}$ Without Investment & 0.02 & 0.02 & 0.01 & 0.01 & 0.06 & 0.02 \\
\hline
\end{tabular}




\section{Figure 3}

\section{Actual against Notional Levels of Leverage}

This figure plots actual against notional levels of leverage at $\tau=+2$. Actual leverage is defined as (total debt)/(total assets) while notional leverage is defined as

$$
\text { NOTNLEV }_{\tau}=\frac{\text { TOTALDEBT }_{\tau}+\sum_{i=-2}^{\tau} e q_{i}}{\text { TOTAL ASSETS }_{\tau}}
$$

at $\tau=+2$ where $e q$ is flow-of-funds EQUITY deflated by the base-level of investment. In eighteen cases where the numerator of notional leverage is negative (i.e. buy-backs exceed total liabilities), leverage was set equal to zero and thirty-two observations where either actual or notional leverage exceeded 1.5 were omitted from the figure (but not the regressions below). The diagonal is plotted for reference and has a slope of one.

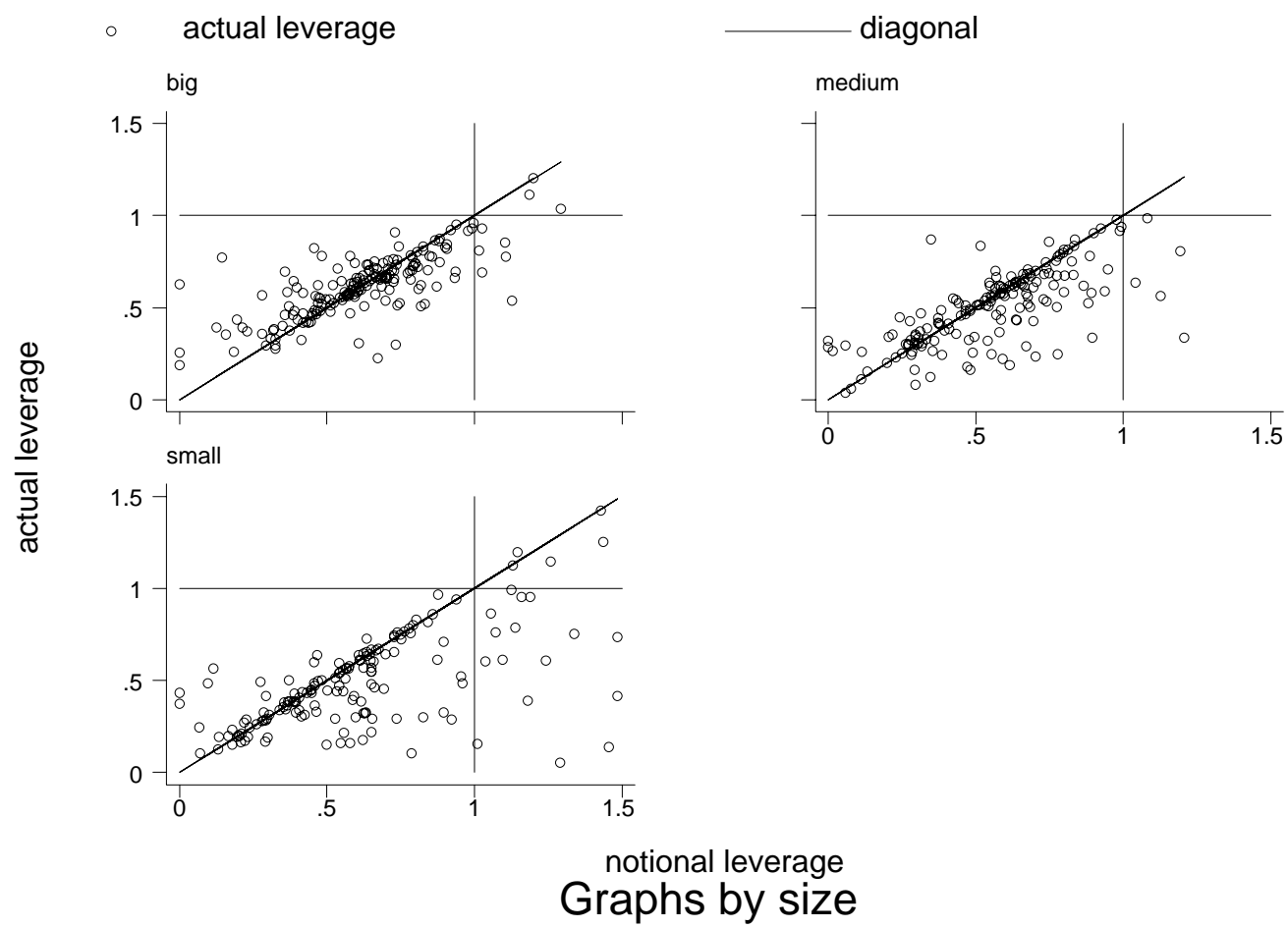




\section{Figure 4}

\section{Leverage Adjustment}

This figure plots leverage adjustment - $L E V_{2}-N O T N L E V_{2}$ - against leverage disturbance NOTNLEV $V_{2}-L E V_{-2}$ - where actual leverage, $L E V$, is defined as (total debt)/(total assets) while notional leverage is defined as

$$
\text { NOTNLEV }_{\tau}=\frac{\text { TOTALDEBT }_{\tau}+\sum_{i=-2}^{\tau} e q_{i}}{\text { TOTAL ASSETS }{ }_{\tau}}
$$

where eq is flow-of-funds EQUITY deflated by the base-level of investment. Some seventy-two observations where initial, actual or notional leverage exceeded one were omitted from both the graphs and the regressions below. The diagonal is plotted for reference with a line of slope minus one.

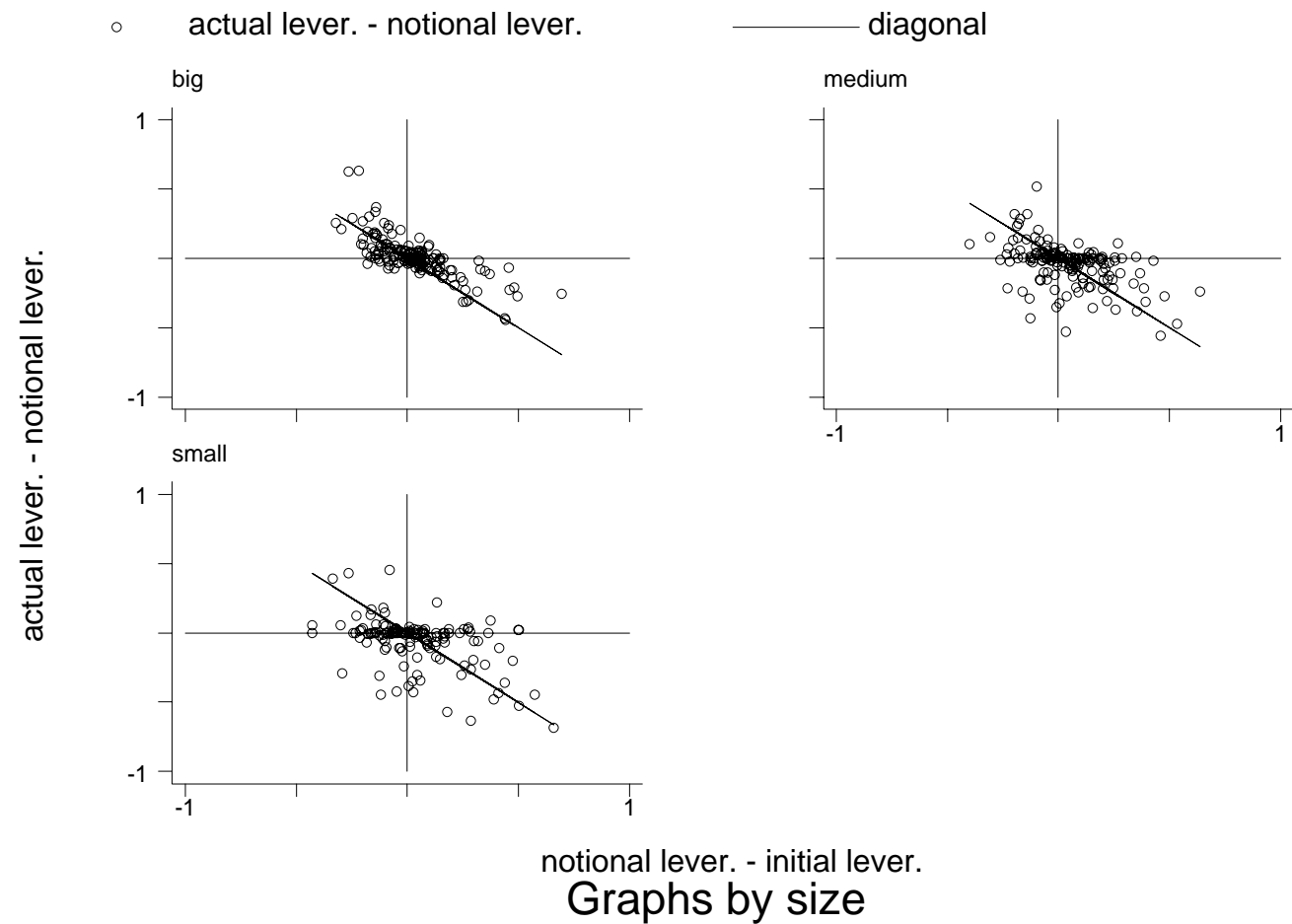




\section{Table 8}

\section{Leverage Adjustment}

The table reports regressions of leverage adjustment $\left(\mathrm{LEV}_{2}-\mathrm{NOTNLEV}_{2}\right)$ on leverage disturbance $\left(\mathrm{NOTNLEV}_{2}-\mathrm{LEV}_{-2}\right.$ ), where LEV, is defined as (total debt)/(total assets) and notional leverage is defined as

$$
\text { NOTNLEV }_{\tau}=\frac{\text { TOTALDEBT }_{\tau}+\sum_{i=-2}^{\tau} e q_{i}}{\text { TOTALASSETS }_{\tau}}
$$

where eq is flow-of-funds EQUITY deflated by the base-level of investment. Results are shown for a sequence of nested samples, where each sub-sample is derived from the previous one by truncation of firms with a notional leverage above a certain threshold. The thresholds used are 1, 0.9, 0.8 and 0.7. The results are recorded separately for large, medium sized and small firms. t-statistics are shown in brackets.

\begin{tabular}{|c|c|c|c|c|}
\hline & \multicolumn{4}{|c|}{ Large Firms } \\
\hline & $\begin{array}{c}\mathrm{NL}<1 \\
(\mathrm{~N}=168)\end{array}$ & $\begin{array}{l}\mathrm{NL}<0.9 \\
(\mathrm{~N}=159)\end{array}$ & $\begin{array}{l}\mathrm{NL}<0.8 \\
(\mathrm{~N}=142)\end{array}$ & $\begin{array}{l}\mathrm{NL}<0.7 \\
(\mathrm{~N}=114)\end{array}$ \\
\hline Leverage disturbance & $\begin{array}{c}-0.66 \\
(-15.01)\end{array}$ & $\begin{array}{c}-0.67 \\
(-14.18)\end{array}$ & $\begin{array}{c}-0.76 \\
(-13.55)\end{array}$ & $\begin{array}{c}-0.78 \\
(-10.76)\end{array}$ \\
\hline \multirow[t]{3}{*}{$\mathbf{R}^{2}$} & 0.58 & $(0.56)$ & 0.57 & 0.51 \\
\hline & \multicolumn{4}{|c|}{ Medium-Sized Firms } \\
\hline & $\begin{array}{c}\mathrm{NL}<1 \\
(\mathrm{~N}=162)\end{array}$ & $\begin{array}{l}\mathrm{NL}<0.9 \\
(\mathrm{~N}=155)\end{array}$ & $\begin{array}{l}\mathrm{NL}<0.8 \\
(\mathrm{~N}=144)\end{array}$ & $\begin{array}{l}\mathrm{NL}<0.7 \\
(\mathrm{~N}=124)\end{array}$ \\
\hline Leverage disturbance & $\begin{array}{c}-0.44 \\
(-7.01)\end{array}$ & $\begin{array}{c}-0.46 \\
(-7.11)\end{array}$ & $\begin{array}{c}-0.41 \\
(-6.10)\end{array}$ & $\begin{array}{c}-0.41 \\
(-5.61)\end{array}$ \\
\hline \multirow[t]{3}{*}{$\mathbf{R}^{2}$} & 0.24 & 0.25 & 0.21 & 0.21 \\
\hline & \multicolumn{4}{|c|}{ Small Firms } \\
\hline & $\begin{array}{c}\mathrm{NL}<1 \\
(\mathrm{~N}=133)\end{array}$ & $\begin{array}{l}\mathrm{NL}<0.9 \\
(\mathrm{~N}=130)\end{array}$ & $\begin{array}{l}\mathrm{NL}<0.8 \\
(\mathrm{~N}=122)\end{array}$ & $\begin{array}{l}\mathrm{NL}<0.7 \\
(\mathrm{~N}=110)\end{array}$ \\
\hline Leverage disturbance & $\begin{array}{c}-0.40 \\
(-5.90)\end{array}$ & $\begin{array}{c}-0.36 \\
(-5.56)\end{array}$ & $\begin{array}{c}-0.34 \\
(-5.17)\end{array}$ & $\begin{array}{c}-0.26 \\
(-3.56)\end{array}$ \\
\hline $\mathbf{R}^{2}$ & 0.20 & 0.19 & 0.18 & 0.10 \\
\hline
\end{tabular}




\section{Figure 5}

\section{Frequency of New Equity Issues}

Panel A shows the size-distribution of equity issues, deflated by base-level of investment, over the period $\tau=-2, \ldots, 2$, over the range [-5,5]. Zero issues (581 observations) and very small issues up to \pm 0.1 ( 872 observations)) have been excluded. A fitted normal distribution is plotted for reference (as a bold line).

Panel B reports the results of tests of skewness and kurtosis (Stata procedure sktest) on the size distributions for the three size samples; a "+" indicates that skewness or kurtosis cannot be rejected at a $1 \%$ confidence interval.

\section{Panel A: Size Distribution of Equity Issues}

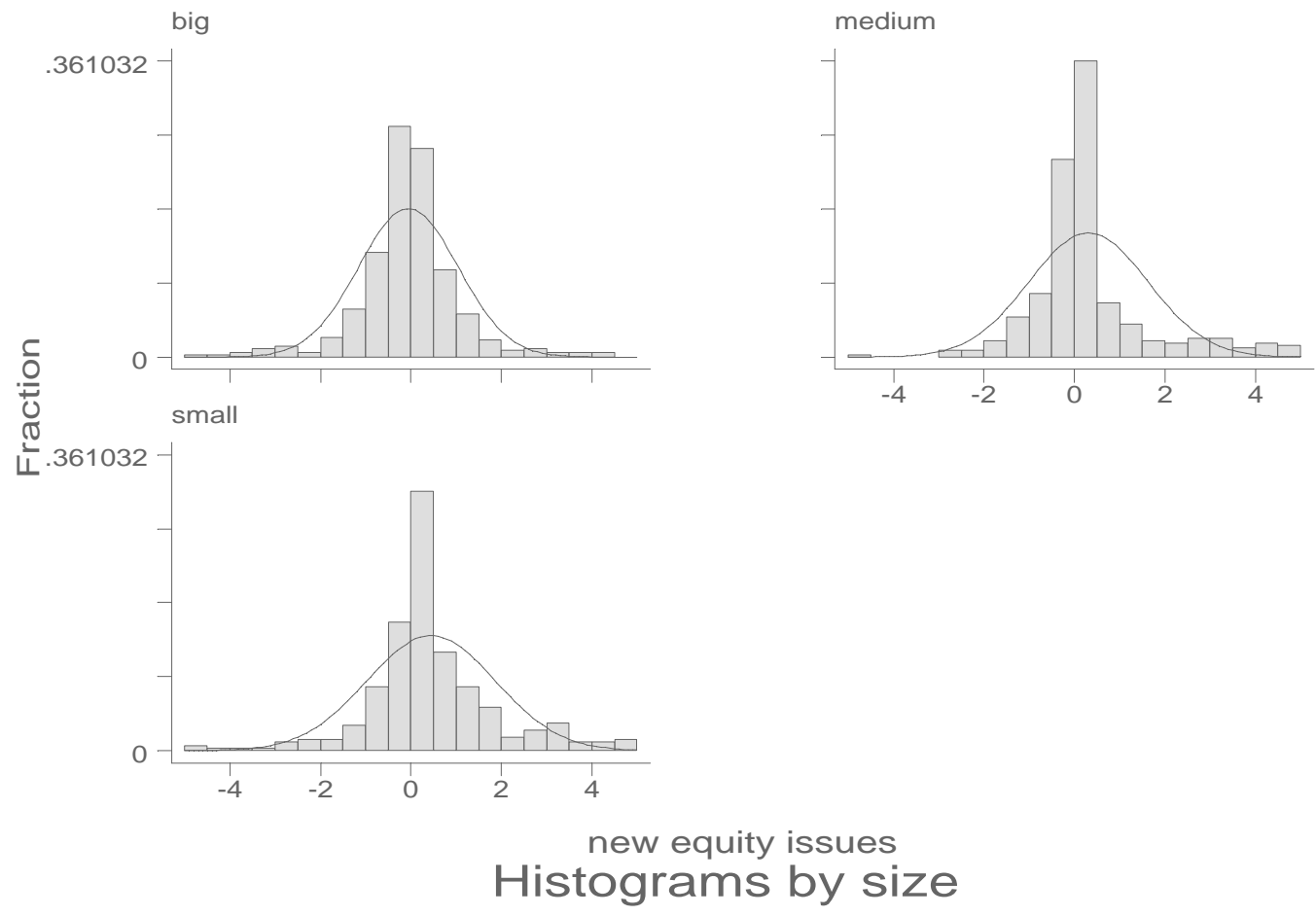

Panel B: Tests of Skewness and Kurtosis

\begin{tabular}{cccc}
\hline & Large Firms & $\begin{array}{c}\text { Medium-Sized } \\
\text { Firms }\end{array}$ & Small Firms \\
\hline Skewness & & + & \\
Kurtosis & + & + & + \\
$\mathbf{N}$ & 387 & 371 & 464 \\
\hline
\end{tabular}




\section{Table 9}

Distribution of Equity Issues by Number of Issues and Accumulated Volume

The table shows the distribution of equity issues (including buy-backs) by the number of issues and accumulated volume over the five-year period $\tau=-2, \ldots, 2$. An issue is defined as flow-of-funds from equity, deflated by the base-level of investment in excess of 0.1 in absolute value. The first column shows the number of issues; the second column shows the frequency (as a percentage) of the number of issues per firm; the third column shows the (average per firm) accumulated cash-flow from equity over the entire five-year period; the fourth column shows (average per firm) accumulated cash-flow from equity in absolute terms over the entire five-year period. t-statistics are shown in brackets.

\begin{tabular}{cccc}
\hline Number of Issues & Frequency (\%) & $\begin{array}{c}\text { Accumulate } \\
\text { Volume }\end{array}$ & $\begin{array}{c}\text { Accumulated Volume } \\
\text { Absolute-Value }\end{array}$ \\
\hline $\mathbf{0}$ & \multicolumn{2}{c}{ Large Firms (387 issues) } \\
$\mathbf{1}$ & 19.6 & $0.02(0.04)$ & $0.11(0.27)$ \\
$\mathbf{2}$ & 20.1 & $0.64(1.21)$ & $1.33(3.19)$ \\
$\mathbf{3}$ & 20.1 & $0.38(0.72)$ & $1.56(3.75)$ \\
$\mathbf{4}$ & 18.4 & $0.02(0.03)$ & $2.47(5.70)$ \\
$\mathbf{5}$ & 8.4 & $0.23(0.28)$ & $2.72(4.23)$ \\
& 13.4 & $-2.42(-3.75)$ & $5.38(10.56)$ \\
$\mathbf{0}$ & Medium-Sized Firms (371 issues) & \\
$\mathbf{1}$ & 19.1 & $0.03(0.04)$ & $0.06(0.09)$ \\
$\mathbf{2}$ & 21.9 & $0.66(0.86)$ & $1.47(2.23)$ \\
$\mathbf{3}$ & 24.1 & $2.65(3.64)$ & $3.51(5.69)$ \\
$\mathbf{4}$ & 13.5 & $1.04(1.06)$ & $3.54(4.21)$ \\
$\mathbf{5}$ & 9.0 & $-0.82(-0.687)$ & $5.56(5.41)$ \\
& 12.4 & $2.78(2.73)$ & $5.77(6.58)$ \\
$\mathbf{0}$ & Small Firms (464 issues) & \\
$\mathbf{1}$ & 15.2 & $0.02(0.01)$ & $0.03(0.01)$ \\
$\mathbf{2}$ & 17.4 & $0.67(0.20)$ & $2.54(0.86)$ \\
$\mathbf{3}$ & 16.3 & $3.69(1.09)$ & $4.51(1.48)$ \\
$\mathbf{4}$ & 15.7 & $9.57(2.78)$ & $10.55(3.40)$ \\
$\mathbf{5}$ & 13.5 & $14.81(3.97)$ & $18.57(5.53)$ \\
& 21.9 & $21.34(7.32)$ & $25.91(9.84)$ \\
\hline
\end{tabular}




\section{Data Appendix \\ Definitions of Cash-Flow Accounts}

The basic accounting identity is:

I=OPR+EQUITY+LTDEBT+OTHER,

(time and company indexes are omitted for brevity). Typically, all items (except OTHER) have a positive sign.

OPR: cash flow from operations (after tax)

ibc: after tax income before extraordinary items

\section{I: fixed investment}

capx: capital expenditure

aqc: acquisition

\section{EQUITY: Equity Finance (net)}

sstk: sale of equity

prstkc: purchase of equity

LTDEBT: long-term debt finance (net):

dltis: issuance of long-term debt

dltr: retirement of long-term debt

\section{OTHER: sum of all other variables}

sppe: sale of property, plant and equipment

apalch: change in account payables and accrued liabilities

txach: change in accrued income taxes

dlcch: change in current debt

esubc: equity in net loss (earnings)

xidoc: extraordinary items

fopo: other funds from operations

exre: exchange rate effect

recch: change in receivables

txdc: deferred tax

aoloch: change in other assets and liabilities

fiao: other financing

ivaco: other investment

sppiv: Loss(Gain) in sale of investment \&PPE

ivch: : increase in investment

siv: sale of investment

ivstch: increase in short-term investment

chech: change in cash and equivalent

invch: change in inventory

\section{Definitions of Balance-Sheet Items}

at $=d t+\operatorname{seq}$

at: total assets

dt: total debt

seq: total equity

ppent: fixed assets. 
Table A1

Extreme Values

In this table we report a procedure to eliminate 17 firms with extreme values. Criterion for 'extreme' values is that 'operations' or 'other' fall outside the [-40,40] segment. All variables are deflated by the base-level of investment, $b$.

\begin{tabular}{ccccc}
\hline & Mean & $\begin{array}{c}\text { Standard } \\
\text { Deviation }\end{array}$ & Minimum & Maximum \\
\hline Investment & -1.45 & 552 Filtered Firms & \\
Operations & 1.34 & 1.85 & -35.75 & -0.53 \\
Equity & 1.17 & 16.24 & -172.71 & 454.75 \\
Debt & 0.09 & 7.65 & -31.14 & 178.96 \\
Other & -1.16 & 20.85 & -59.81 & 137.85 \\
535 Filtered Firms (After the Elimination of Extreme Values) \\
Investment & $-1,42$ & 1.69 & -35.75 & -0.53 \\
Operations & 0.99 & 3.81 & -33.42 & 25.48 \\
Equity & 0.67 & 3.84 & -31.14 & 45.94 \\
Debt & 0.00 & 2.89 & -36.95 & 37.33 \\
Other & -2.23 & 4.73 & -39.97 & 38.60 \\
\hline
\end{tabular}


Table A2

Industry Breakdown

\begin{tabular}{|c|c|c|}
\hline Industry Name & SIC codes & $\mathbf{N}$ \\
\hline Agriculture & $1-999$ & 3 \\
\hline Mining & $1000-1299$ & 7 \\
\hline Oil and gas extraction & $1300-1399$ & 24 \\
\hline Construction related & $1400-1799$ & 10 \\
\hline Food & 2000-2099 & 25 \\
\hline Tobacco & $2100-2199$ & 2 \\
\hline Textile & $2200-2299$ & 7 \\
\hline Apparel & $2300-2399$ & 11 \\
\hline Lumber and wood & $2400-2499$ & 5 \\
\hline Furniture and fixture & $2500-2599$ & 5 \\
\hline Paper & $2600-2699$ & 11 \\
\hline Printing and publishing & $2700-2799$ & 13 \\
\hline Chemicals & $2800-2899$ & 46 \\
\hline Petrol refining & $2900-2999$ & 6 \\
\hline Rubber and plastic & $3000-3099$ & 17 \\
\hline Leather & $3100-3199$ & 3 \\
\hline Stone an concrete & $3200-3299$ & 4 \\
\hline Primary metal & $3300-3399$ & 12 \\
\hline Other metal & $3400-3499$ & 9 \\
\hline Machinery & $3500-3599$ & 42 \\
\hline Electrical products & $3600-3699$ & 49 \\
\hline Transportation equipment & $3700-3799$ & 8 \\
\hline Other: watches, photos & $3800-3899$ & 32 \\
\hline Miscellaneous products & 3900-3999 & 7 \\
\hline Transportation services & $4000-4799$ & 12 \\
\hline Communication & $4800-4899$ & 18 \\
\hline Wholesale & $5000-5199$ & 35 \\
\hline Retail & $5200-5999$ & 36 \\
\hline Other services & 7000-9099 & 56 \\
\hline Other & Other & 20 \\
\hline Whole Population & & 535 \\
\hline
\end{tabular}

